Atmos. Chem. Phys., 13, 9801-9818, 2013

www.atmos-chem-phys.net/13/9801/2013/

doi:10.5194/acp-13-9801-2013

(c) Author(s) 2013. CC Attribution 3.0 License.

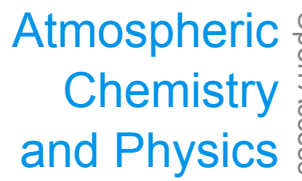

(C) (1)

\title{
Tropical tropopause ice clouds: a dynamic approach to the mystery of low crystal numbers
}

\author{
P. Spichtinger ${ }^{1}$ and M. Krämer ${ }^{2}$ \\ ${ }^{1}$ Institut für Physik der Atmosphäre, Johannes Gutenberg-Universität, Mainz, Germany \\ ${ }^{2}$ Institut für Energie- und Klimaforschung (IEK-7), Forschungszentrum Jülich, Jülich, Germany \\ Correspondence to: P. Spichtinger (spichtin@uni-mainz.de)
}

Received: 24 July 2012 - Published in Atmos. Chem. Phys. Discuss.: 25 October 2012

Revised: 27 August 2013 - Accepted: 29 August 2013 - Published: 7 October 2013

\begin{abstract}
The occurrence of high, persistent ice supersaturation inside and outside cold cirrus in the tropical tropopause layer (TTL) remains an enigma that is intensely debated as the "ice supersaturation puzzle". However, it was recently confirmed that observed supersaturations are consistent with very low ice crystal concentrations, which is incompatible with the idea that homogeneous freezing is the major method of ice formation in the TTL. Thus, the tropical tropopause "ice supersaturation puzzle" has become an "ice nucleation puzzle". To explain the low ice crystal concentrations, a number of mainly heterogeneous freezing methods have been proposed. Here, we reproduce in situ measurements of frequencies of occurrence of ice crystal concentrations by extensive model simulations, driven by the special dynamic conditions in the TTL, namely the superposition of slow large-scale updraughts with high-frequency short waves. From the simulations, it follows that the full range of observed ice crystal concentrations can be explained when the model results are composed from scenarios with consecutive heterogeneous and homogeneous ice formation and scenarios with pure homogeneous ice formation occurring in very slow $\left(<1 \mathrm{~cm} \mathrm{~s}^{-1}\right)$ and faster $\left(>1 \mathrm{~cm} \mathrm{~s}^{-1}\right)$ largescale updraughts, respectively. This statistical analysis shows that about $80 \%$ of TTL cirrus can be explained by "classical" homogeneous ice nucleation, while the remaining $20 \%$ stem from heterogeneous and homogeneous freezing occurring within the same environment. The mechanism limiting ice crystal production via homogeneous freezing in an environment full of gravity waves is the shortness of the gravity waves, which stalls freezing events before a higher ice crystal concentration can be formed.
\end{abstract}

\section{Introduction}

Water vapour is the most important natural greenhouse gas. However, in the stratosphere, an increase in water vapour would possibly result in an overall cooling of the lower stratosphere but a slight warming of Earth's surface temperature (Forster and Shine, 2002). Most trace substances enter the stratosphere through the tropical tropopause layer (TTL), located between the main level of convective outflow, $150 \mathrm{hPa}$, and about $70 \mathrm{hPa}$ (Fueglistaler et al., 2009a). The TTL water vapour budget, and thus the exchange with the stratosphere, depends crucially on the occurrence and properties of ice clouds in this cold region $(T<200 \mathrm{~K})$. It is believed that homogeneous freezing of liquid solution particles (Koop et al., 2000), which dominate the particle population, is the preferred pathway of ice formation in the lowtemperature regime $(T<235 \mathrm{~K})$. High water vapour supersaturation with respect to ice is required to initiate homogeneous ice nucleation. The number of emerging ice crystals depends on temperature and the ambient relative humidity over ice (RHi). Vertical upward motions lead to adiabatic expansions of the air parcels and therefore to a (strong) increase in RHi, which will produce large amounts of ice crystals (see Sect. 3.2).

In the TTL, very slow large-scale updraughts prevail ( $\leq 0.01 \mathrm{~m} \mathrm{~s}^{-1}$; e.g. Virts et al., 2010), which lead to low ice crystal concentrations $\left(\leq 0.1 \mathrm{~cm}^{-3}\right)$. However, tropical deep convection is a source of intrinsic gravity waves in this region (e.g. Fritts and Alexander, 2003), which consequently initiate much higher vertical velocities and, therefore, higher ice crystal number concentrations (mostly $>0.3 \mathrm{~cm}^{-3}$; e.g. Jensen et al., 2010) are expected. Since the many ice crystals 
grow rapidly by water vapour diffusion (Korolev and Mazin, 2003), it is expected that the initially high ice supersaturation quickly reduces to thermodynamical equilibrium (ice saturation) after ice formation.

In contrast, over the last few years high and persistent ice supersaturations were observed inside and outside ice clouds in the cold TTL in several airborne field campaigns, creating a discussion called the "supersaturation puzzle" (Peter et al., 2006). A step forward in this discussion was made recently: Krämer et al. (2009) observed ice crystal concentrations much lower than expected (most often $<0.1 \mathrm{~cm}^{-3}$ ), but consistent with the high supersaturations measured. These observations turned the "supersaturation" into a "nucleation puzzle", which is supported by earlier measurements of low ice crystal numbers (McFarquhar et al., 2000; Thomas et al., 2002; Lawson et al., 2008). The "nucleation puzzle" is currently being intensely discussed and other nucleation pathways suppressing, modifying or replacing homogeneous freezing have been proposed (Kärcher and Koop, 2005; Gensch et al., 2008; Murray, 2008; Zobrist et al., 2008; Krämer et al., 2009; Spichtinger and Gierens, 2009c; Murray et al., 2010; Jensen et al., 2013). Most of the former approaches explaining the TTL ice nucleation are of a chemical or microphysical nature. Here, we present extensive model studies of ice cloud formation under dynamical conditions typical for the TTL. By directly comparing model simulations and observations, we claim that the special TTL dynamics namely a superposition of very slow large-scale updraughts with high-frequency short waves - can produce about $80 \%$ of the observed low numbers of ice crystals by the "classical" homogeneous freezing of solution droplets (Koop et al., 2000 ), while about $20 \%$ is formed via homogeneous and heterogeneous freezing occurring within the same environment.

The study is structured as follows. In the next section, we present an introduction to ice formation processes in homogeneous freezing events and the impact of local dynamics. Section 3 presents idealized ice cloud simulations in order to show the impact of the superposition of motions on different spatial/temporal scales. In Sect. 4, the special dynamic conditions in the TTL are briefly summarized (large-scale motion vs. gravity waves) before realistic simulations of ice formation in the TTL are presented and discussed in comparison to observations in Sect. 5. In Sect. 6, the results and their interpretation are discussed in combination with other approaches. We then end with the conclusions.

\section{Basics of ice formation}

\subsection{The ice cloud model}

The simulations in this study are carried out using a box model with a state-of-the-art bulk microphysics scheme developed for cold ice clouds $(T<235 \mathrm{~K})$. The model is described in detail in Spichtinger and Gierens (2009a) and
Spichtinger and Cziczo (2010), thus here only some key properties are briefly described. The double-moment scheme with prognostic equations for ice crystal mass and number concentration is based on general moments of the underlying mass distribution(s) of the ice crystals, which are assumed to be lognormal with a fixed geometric standard deviation of mass $\sigma_{\mathrm{m}}=2.85$, corresponding to a geometric standard deviation of length $\sigma_{\mathrm{L}} \sim 1.4-1.6$. The dominant processes in the low-temperature regime are parameterized, as nucleation of ice crystals, diffusional growth, and evaporation and sedimentation of ice crystals. The formulation using general moments leads to a consistent representation of these processes. The model can arbitrarily treat many classes of ice, each of them containing prognostic variables for ice as well as background aerosol mass and number concentrations. Thus, for the ice particles, there are complementary aerosol particles which control the ice formation process. In contrast to the usual treatment in bulk moment schemes used in other models (e.g. COSMO, see Seifert and Beheng, 2006), the different classes of ice are differentiated by their formation mechanism (e.g. heterogeneously vs. homogeneously formed ice). The aggregation of ice crystals is not included here, because this process is assumed to be of minor importance at low temperatures (see e.g. Kajikawa and Heymsfield, 1989). For homogeneous freezing of aqueous solution droplets (in short: homogeneous ice nucleation), sulfuric acid $\left(\mathrm{H}_{2} \mathrm{SO}_{4}\right)$ is assumed to be the background aerosol. For details of the freezing process, see Sect. 2.2. The $\mathrm{H}_{2} \mathrm{SO}_{4}$ background aerosol droplets are distributed according to a lognormal size distribution with a fixed geometric standard deviation; the modal radius of the distribution is initialized at the beginning but can change due to nucleation processes, since for frozen aerosol droplets, it is assumed that the aerosol is trapped in the ice crystals thus removed from the background aerosol. The parameterization of the diffusional growth process is extended to the temperature and pressure range relevant for the TTL (see also Krämer et al., 2009), i.e. $T \geq 178 \mathrm{~K}$, $p \geq 50 \mathrm{hPa}$.

\subsection{Homogeneous freezing of solution droplets: RHi variations and ice crystal numbers}

First, we will briefly recapitulate the mechanism of homogeneous freezing of aqueous solution droplets. At low temperatures, pre-existing soluble aerosol particles (e.g. $\mathrm{H}_{2} \mathrm{SO}_{4}$ ) can take up water via the Koehler theory, thus growing to form aqueous solution droplets, i.e. the weight fraction of the solute is quite small. These droplets can be supercooled by a few degrees until they freeze spontaneously. The nucleation rate for homogeneous freezing of solution droplets can be described using water activity $a_{\mathrm{w}}$ (see e.g. Koop et al., 2000). Thus, the nucleation rate for a given droplet of a certain diameter depends only on temperature and on the environmental relative humidity. Starting with a "dry" size distribution of soluble aerosol particles $f(r)$, a size distribution 
of aqueous solution droplets $f_{\mathrm{d}}(r)$ results from the Koehler theory. Note that the distribution $f_{\mathrm{d}}(r)$ also depends on environmental temperature and humidity. The distributions are normalized by the total number of aerosol particles $N_{\mathrm{a}}$. Using the volume nucleation rate $J=J\left(a_{\mathrm{w}}, T\right)=J(\mathrm{RHi}, T)$, we can describe the number of nucleated ice crystals per time interval $\Delta t$ using

$$
\Delta N=N_{\mathrm{a}} \int_{0}^{\infty} f_{\mathrm{d}}(r)\left(1-\exp \left(-J \frac{4}{3} \pi r^{3} \Delta t\right)\right) \mathrm{d} r
$$

Assuming the existence of the third general moment of the distribution $f_{\mathrm{d}}(r)$, we can describe the ice crystal production rate using the following expression as derived from Eq. (1):

$$
\frac{\mathrm{d} N}{\mathrm{~d} t}=N_{\mathrm{a}} \frac{4}{3} \pi \mu_{3}[r] \cdot J
$$

where $\mu_{k}[r]:=\int_{0}^{\infty} f_{\mathrm{d}}(r) r^{k} \mathrm{~d} r$. Note that here an only marginal change of temperature and humidity causes $J$ to vary over several orders of magnitude (see Koop et al., 2000). The nucleation process, involving the nucleation rate based on the environmental conditions, is one important factor for determining the number of ice crystals formed in a typical cooling event, but other processes might be important as well. For a detailed analysis, we investigated a typical nucleation event. We assumed an air parcel rising with a prescribed vertical velocity; the system is isolated, i.e. no exchange with the environment is allowed. Here we also assumed a constant vertical velocity. To evaluate the time evolution of the relative humidity, we considered the total derivative of the relative humidity with respect to ice, i.e.

$$
\begin{aligned}
\mathrm{RHi} & =100 \% \frac{p \cdot q}{\epsilon \cdot p_{\text {ice }}(T)}, \\
\frac{\mathrm{dRHi}}{\mathrm{d} t}= & \underbrace{\frac{\partial \mathrm{RHi}}{\partial T} \frac{\mathrm{d} T}{\mathrm{~d} t}+\frac{\partial \mathrm{RHi}}{\partial p} \frac{\mathrm{d} p}{\mathrm{~d} t}}_{\approx \text { adiabatic expansion }}+\underbrace{\frac{\partial \mathrm{RHi}}{\partial q} \frac{\mathrm{d} q}{\mathrm{~d} t}}_{\text {growth }} .
\end{aligned}
$$

Then, we inspected the terms in Eq. (4) in order to examine a homogeneous nucleation event. First, we investigated the change in temperature and pressure, assuming just external changes driven by the vertical updraught. The temperature rate $\mathrm{d} T / \mathrm{d} t$ can be described using the vertical updraught $w$, as

$$
\frac{\mathrm{d} T}{\mathrm{~d} t}=\frac{\mathrm{d} T}{\mathrm{~d} z} \frac{\mathrm{d} z}{\mathrm{~d} t}=-\frac{g}{c_{p}} w=-\Gamma w,
$$

where $g$ and $c_{p}$ denote the gravity acceleration and the specific heat capacity for constant pressure, respectively. $\Gamma=\frac{g}{c_{p}}$ is the dry adiabatic lapse rate. Using the Clausius-Clapeyron equation and the isentropic coefficient $\kappa=R / c_{p}=2 / 7$ for air and assuming pure adiabatic temperature changes, we can reformulate the first two terms on the right-hand side of
Eq. (4) in a more natural way:

$$
\frac{\partial \mathrm{RHi}}{\partial T} \frac{\mathrm{d} T}{\mathrm{~d} t}+\frac{\partial \mathrm{RHi}}{\partial p} \frac{\mathrm{d} p}{\mathrm{~d} t}=-\frac{\mathrm{RHi}}{T}\left(\frac{L}{R_{v} T}-\frac{1}{\kappa}\right) \frac{\mathrm{d} T}{\mathrm{~d} t} .
$$

Please note that the first term in brackets is usually about one order of magnitude larger than the absolute value of the second term for the temperature range relevant for the existence of ice crystals $(180 \leq T \leq 273 \mathrm{~K})$. From Eqs. (5) and (6), we can clearly see that adiabatic expansion (i.e. vertical updraughts with positive $w$ values) leads to an increase in relative humidity.

The last term on the right-hand side of Eq. (4) describes changes in specific humidity, which only occur if ice particles with a bulk mass mixing ratio $q_{\mathrm{c}}$ exist inside the air parcel (because exchange with the environment is not permitted), i.e. $\mathrm{d} q / \mathrm{d} t=-\mathrm{d} q_{\mathrm{c}} / \mathrm{d} t$, constituting a sink for relative humidities in the range $\mathrm{RHi}>100 \%$. Thus, in the case of ice particles inside the box and for relative humidities larger than saturation, there are two competing terms; a source and a sink. We then investigate their relative role for a homogeneous nucleation event.

For this purpose, we simulated a situation of a constant updraught, i.e. a standard cooling event, indicated by red lines in all three panels of Fig. 1. The box model is used including processes of (a) homogeneous freezing of aqueous solution droplets and (b) diffusional growth/evaporation only; sedimentation is ignored in order to reduce the complexity of the experiment. We specified one class of homogeneously frozen ice crystals. For the soluble background aerosol, which forms the solution droplets that trigger homogeneous nucleation later on, we prescribed a dry $\mathrm{H}_{2} \mathrm{SO}_{4}$ aerosol with lognormal distribution, a geometric standard deviation of $\sigma_{\mathrm{r}}=1.5$, and initial modal radius $r_{\mathrm{m}}=25 \mathrm{~nm}$. The background aerosol number concentration was set to $N_{\mathrm{a}}=$ $300 \mathrm{~cm}^{-3}$, which is more representative for extra-tropical tropospheric conditions. For the standard cooling event with initial conditions of $T_{\text {init }}=220 \mathrm{~K}$ and $p_{\text {init }}=300 \mathrm{hPa}$, and a prescribed persistent updraught of $w=0.1 \mathrm{~ms}^{-1}$, the relative humidity increased (red line in upper panel of Fig. 1). At some point, the threshold RHi for homogeneous nucleation of droplets of a certain size (black line: threshold for $\sim 250 \mathrm{~nm}$ droplets) was reached and thus ice crystals were formed via homogeneous freezing. However, these ice crystals were quite small. Their surface was small so that their ability to deplete water vapour was quite limited; therefore, the relative humidity continued to increase; i.e. the source of supersaturation due to adiabatic cooling dominated over the sink of diffusional growth. The increasing relative humidity led to further ice crystal nucleation. After some time (around $t \sim 350 \mathrm{~s}$ ), the size of the ice crystals increased, allowing the crystals to deplete the water vapour efficiently, balancing the source via adiabatic cooling. After $t \sim 355 \mathrm{~s}$, the sink was stronger than the source and the relative humidity decreased (i.e. there was a net sink), although there was still a source of supersaturation by adiabatic cooling. At 

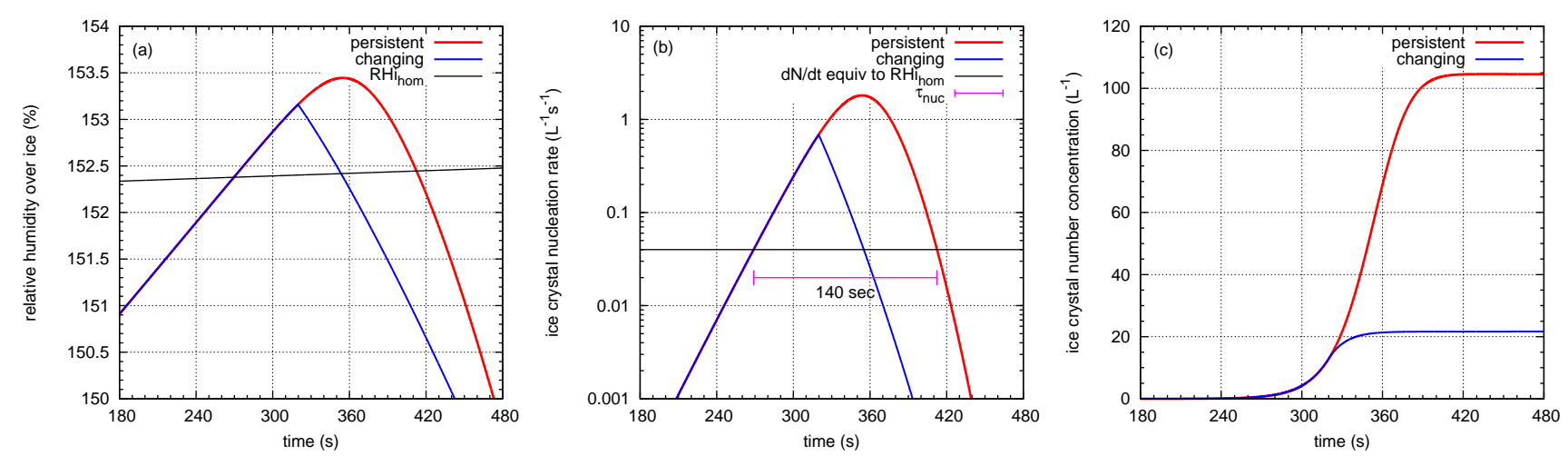

Fig. 1. Example of the impact of changing updraughts on the formation of ice crystals via homogeneous freezing of solution droplets. The three panels show the time evolution of (a) relative humidity with respect to ice, (b) ice crystal nucleation rate, and (c) ice crystal number concentration. Red curves indicate a constant persistent updraught of $w=0.1 \mathrm{~m} \mathrm{~s}^{-1}$, whereas blue curves indicate a scenario with a constant updraught of $w=0.1 \mathrm{~ms}^{-1}$ until $t=320 \mathrm{~s}$, followed by a constant downdraught of $w=-0.1 \mathrm{~ms}^{-1}$. The black line in panel (a) indicates the homogeneous nucleation threshold for solution droplets of size $r=0.25 \mu \mathrm{m}$; this threshold corresponds to a production rate of $\mathrm{d} N_{i} / \mathrm{d} t=$ $0.04 \mathrm{~L}^{-1} \mathrm{~S}^{-1}$ as indicated in panel (b).

later times, the relative humidity crossed the homogeneous nucleation threshold, approaching from higher values, thus ice crystal formation was shut down. Until this threshold was reached, there was still ice crystal nucleation. This scenario is used quite often in many idealized studies in order to investigate ice formation at constant updraughts under certain conditions (see, e.g. Kärcher and Lohmann, 2002; Hoyle et al., 2005; Barahona and Nenes, 2008; Spichtinger and Gierens, 2009a; Spichtinger and Cziczo, 2010), leading to a one-toone relationship between vertical updraughts and ice crystal number concentrations produced in such cooling events. The main issue here is that the vertical updraught was kept constant during the whole cooling event, which lasted about $\tau_{\text {nuc }} \approx 140$ s. In the middle panel of Fig. 1, the ice crystal nucleation rate is shown, including the nucleation time $\tau_{\text {nuc }}$, whereas in the right panel of the figure, the evolution of the ice crystal number concentration is shown. Since we show a scenario at quite high temperatures (initially $T=220 \mathrm{~K}$ ), the ice crystal number concentration formed in the cooling event is quite low $\left(N \approx 105 \mathrm{~L}^{-1}\right)$.

Next, we will look at the case of a change in vertical updraught during the nucleation event (i.e. within the time interval $\tau_{\text {nuc }}$ ). To demonstrate this issue, we investigated the following idealized scenario. We started with a constant updraught of $w=0.1 \mathrm{~m} \mathrm{~s}^{-1}$, but at $t=320 \mathrm{~s}$ we switched to the value of $w=-0.1 \mathrm{~m} \mathrm{~s}^{-1}$, i.e. the updraught was turned into a downdraught of equal strength (Fig. 1, blue lines). Until the change in updraught, the simulations were identical. However, when the cooling process was turned into a warming process, the relative humidity decreased at approximately the same rate as it increased before. The homogeneous nucleation threshold was reached soon after this (at $t \sim 355 \mathrm{~s}$, incidentally approximately the time where the maximum RHi values were reached in the reference simulation), thus the nucleation event was stopped much earlier, as can be seen in the ice crystal nucleation rate in the middle panel. This led to a significantly lower ice crystal number concentration, compared to the reference simulation. When vertical velocities were modified from $w=0.1 \mathrm{~m} \mathrm{~s}^{-1}$ to $w=-0.1 \mathrm{~m} \mathrm{~s}^{-1}$ during the nucleation event, the final ice crystal number concentration was about $N \approx 20 \mathrm{~L}^{-1}$.

The key finding of these investigations is that a changing vertical updraught could massively influence the number of ice crystals produced during a nucleation event. This finding was used to simulate the small ice crystal number concentrations found in the TTL. The updraught was then modified by superimposing a wave structure to a very slow vertical motion. As we will show later (Sect. 4), a varying updraught in the TTL is triggered by high-frequency gravity waves.

\section{Idealized TTL ice cloud simulations}

In this section, the role of different superimposed vertical velocity components in the formation of ice crystals will be investigated by means of idealized model simulations relevant to the situation in the TTL.

\subsection{Model set-up}

To perform the idealized TTL ice cloud simulations, we used the box model described in Sect. 2.1 with the following model set-up: as in the simulations described in the previous section, only one class of ice formed by homogeneous nucleation was assumed; the same background aerosol conditions were prescribed as in Sect. 2; i.e. we assume pure homogeneous freezing of aqueous solution droplets containing sulfuric acid. In a first step, we established a reliable relationship between vertical updraught and ice crystal number 
concentrations for the temperature range $185 \leq T \leq 200 \mathrm{~K}$ and the vertical velocity range of $0.01 \leq w \leq 10 \mathrm{~ms}^{-1}$. In our model simulations, the aerosol particles were removed from the background as soon as ice crystals were formed. Hence, the background aerosol was reduced during nucleation events and acted as a limiting factor for the ice crystal number concentrations formed. As the initial pressure of all simulations we used $p_{\text {init }}=100 \mathrm{hPa}$, motivated by aircraft measurements (see, e.g. Schiller et al., 2008).

In a second step, we investigated the influence of changing updraughts in a more relevant but still idealized set-up. For this purpose, we specified two different types of vertical velocity; a large-scale component $w_{\mathrm{LS}}$ and a wave-like signature, given by a pure sine wave. According to Eq. (6) the change in relative humidity is driven by temperature changes, which correspond to vertical velocity via Eq. (5) assuming adiabatic changes. The temperature evolution for the special case of a large-scale updraught superimposed by a highfrequency monochromatic wave with an intrinsic frequency $\omega=\frac{2 \pi}{\tau}$ can be described as follows:

$$
\begin{aligned}
T(t) & =T_{\text {init }} \underbrace{-\Gamma \cdot w_{\mathrm{LS}} \cdot t}_{\text {large scale }} \underbrace{+A_{\mathrm{T}} \cos (\omega t)}_{\text {wave }} \\
& =T_{\text {init }}+T_{\mathrm{LS}}(t)+T_{\text {wave }}(t) .
\end{aligned}
$$

Thus, the temperature rate is given by the following equation:

$$
\frac{\mathrm{d} T}{\mathrm{~d} t}=\underbrace{-\Gamma \cdot w_{\mathrm{LS}}}_{\text {large scale }} \underbrace{-A_{\mathrm{T}} \omega \sin (\omega t)}_{\text {wave }}=\left.\frac{\mathrm{d} T}{\mathrm{~d} t}\right|_{\text {large scale }}+\left.\frac{\mathrm{d} T}{\mathrm{~d} t}\right|_{\text {wave. }}
$$

Using Eq. (5) we end up with an expression for the vertical velocity, which is consistent with Eq. (7):

$$
\begin{aligned}
w(t)=\frac{\mathrm{d} z}{\mathrm{~d} t} & =w_{\mathrm{LS}}+\frac{c_{p}}{g} \omega A_{\mathrm{T}} \sin (\omega t) \\
& =w_{\mathrm{LS}}+A_{\mathrm{w}} \sin (\omega t)=w_{\mathrm{LS}}+w_{\text {wave }}(t) .
\end{aligned}
$$

For our idealized set-up we choose a time period of $\tau=$ $500 \mathrm{~s}$, i.e. $\omega=\frac{2 \pi}{\tau} \approx 0.0126 \mathrm{~s}^{-1}$; the amplitude is set to a value of $A_{w}=1.25 \mathrm{~m} \mathrm{~s}^{-1}$, corresponding to a temperature amplitude of about $A_{\mathrm{T}} \approx 1 \mathrm{~K}$. For the large-scale component we distinguished between two different regimes, i.e. a low regime $\left(w_{\mathrm{LS}}=0.008 \mathrm{~m} \mathrm{~s}^{-1}\right)$ and a high regime $\left(w_{\mathrm{LS}}=\right.$ $0.03 \mathrm{~m} \mathrm{~s}^{-1}$ ). In Sect. 5, we will show that the choice of these values was not arbitrary but motivated by the realistic dynamic conditions in the TTL (see Sect. 4).

\subsection{Results}

In Fig. 2, the relationship between constant and persistent vertical updraughts and ice crystal number concentrations is shown, representative of conditions in the TTL. For low vertical velocities, we can see a kind of power law (note the

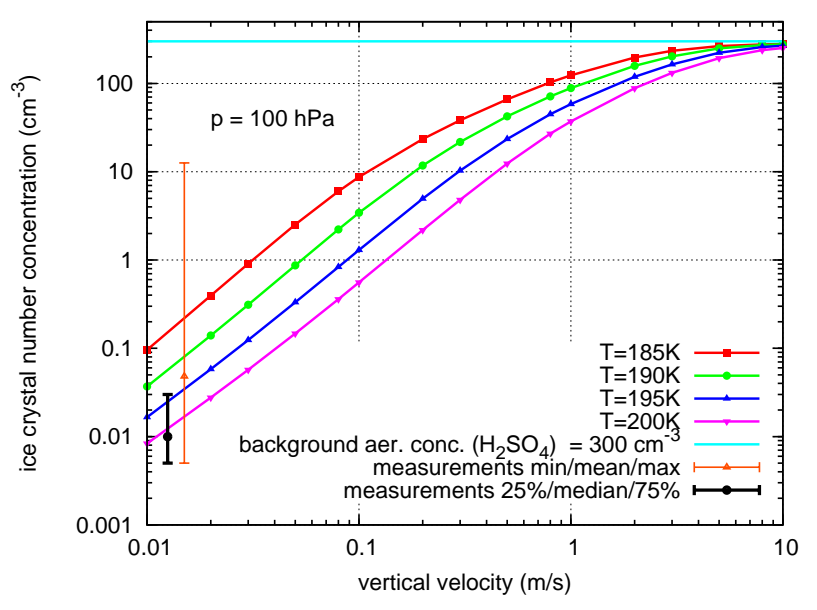

Fig. 2. Ice crystal number concentration as formed in idealized simulations with a prescribed constant updraught under conditions typical for the TTL $(T=185 / 190 / 195 / 200 \mathrm{~K}$ - colour code indicated in the inset legend,$- p=100 \mathrm{hPa}$ ). Note that due to a finite background aerosol concentration, the ice crystal number concentration is limited by the aerosol concentration. This leads to the asymptotic behaviour of curves for $w>0.5 \mathrm{~ms}^{-1}$. In addition, the measured ice crystal number concentrations are indicated (Krämer et al., 2009); the vertical orange bar indicates minimal and maximal concentrations and the mean value, whereas the vertical black bar indicates the 25 and $75 \%$ percentiles as well as the median value.

double-logarithmic plot). However, for larger values of $w$ the increase slows down as a result of the limitation of the nucleation process by the pre-existing background aerosol (see also Spichtinger and Gierens, 2009a). Under the usual assumption that the TTL is full of gravity waves with vertical velocities $w \geq 0.2 \mathrm{~ms}^{-1}$, it could be argued that only ice crystal number concentrations in the range $N \geq 1 \mathrm{~cm}^{-3}$ should occur. However, as stated in the introduction, this is the essence of the nucleation puzzle, because much smaller values have been obtained in observations (see Fig. 3). To clarify this central point in our study, we then superimposed a constant large-scale vertical motion $w_{\mathrm{LS}}$ and a highfrequency wave $w_{\text {wave }}(t)$, i.e. $w(t)=w_{\mathrm{LS}}+w_{\text {wave }}(t)$ or in temperature variations $T(t)=T_{\text {init }}+T_{\mathrm{LS}}(t)+T_{\text {wave }}(t)$.

The results of ice crystal formation in this scenario are shown in Fig. 4. We started with the faster motion regime $\left(w_{\mathrm{LS}}=0.03 \mathrm{~m} \mathrm{~s}^{-1}\right.$, top right panel), which constitutes the well-known case described by Lin et al. (1998): the relative humidity increased because of the slow vertical updraught and the high-frequency wave (see red line in top right panel of Fig. 4). At $t \sim 1400 \mathrm{~s}$ and about $t \sim 1950 \mathrm{~s}$, the relative humidity peaked as the wave was pushed over the threshold for homogeneous ice nucleation by the large-scale updraught. The combination of the short wave and the large-scale updraught resulted in a strong change in $\mathrm{RHi}$, causing quite a vigorous increase in the ice nucleation rate. High ice crystal number concentrations were formed in two overshoots, 


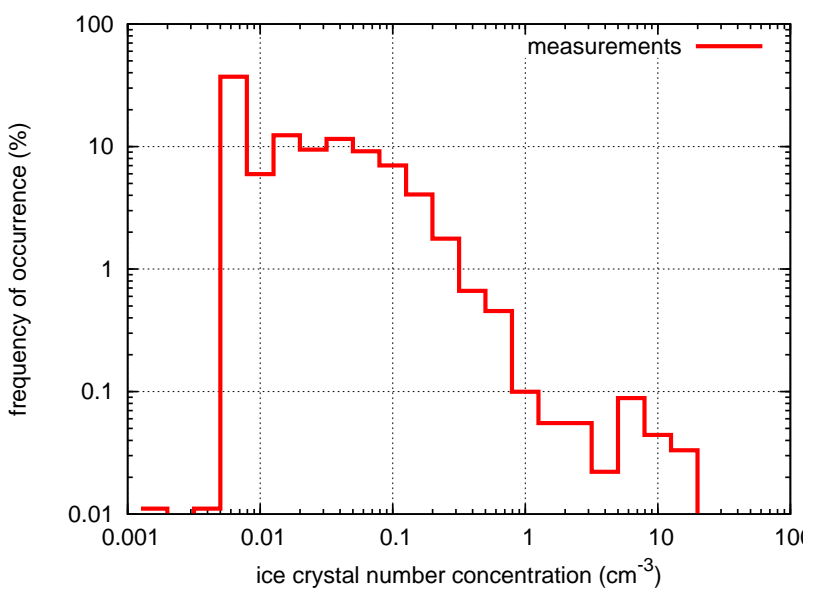

Fig. 3. Measured ice crystal number concentration distribution in the temperature range $T<200 \mathrm{~K}$, from Krämer et al. (2009).

which can be seen in the middle right panel of Fig. 4 (red line). Additionally, the two nucleation events can be seen in the ice crystal production rate $\mathrm{d} N_{i} / \mathrm{d} t$ (Fig. 4, bottom right panel). The high ice crystal number concentrations led to an effective diffusional growth, the gas phase water was depleted quite fast causing the ice supersaturation to relax to values around saturation. The final ice crystal number concentration was much higher than that in the scenario with a constant updraught of only $w_{\mathrm{LS}}=0.03 \mathrm{~m} \mathrm{~s}^{-1}$ (blue line in the middle right panel of Fig. 4). The maximum ice crystal number concentrations for these two cases were $N_{i} \sim 0.33 \mathrm{~cm}^{-3}$ (constant updraught, blue line) and $N_{i} \sim 11.1 \mathrm{~cm}^{-3}$ (induced by the short wave, red line). Therefore, there was an enhancement in ice crystal number concentrations of about two orders of magnitude.

In the case of a much slower updraught $\left(w_{\mathrm{LS}}=\right.$ $0.008 \mathrm{~m} \mathrm{~s}^{-1}$ ) with a superimposed short wave (left panel in Fig. 4, red lines), the picture was different from what was expected. The very slow lifting of the air parcel pushed the RHi peaks of the wave very slowly towards the homogeneous nucleation thresholds (red line in left panel of Fig. 4). The first nucleation events were very weak (see production rate $\mathrm{d} N_{i} / \mathrm{d} t$ in Fig. 4, bottom left panel), because the overshoots were very small and the change in RHi was smaller than for a faster large-scale updraught. However, in these first nucleation events a few ice crystals were formed, which began depleting the available water vapour. In subsequent nucleation events, more ice crystals were formed, but the rates remained quite low because of the gentle overshoots. The available ice crystals also reduced the ice supersaturation quite slowly, resulting in a slow decrease in RHi and thus in a gentle shutdown of the nucleation. This process finally resulted in a small ice crystal number concentration, which is comparable to concentrations produced by the weak constant updraught (blue line). Consequently, the RHi decreased only slowly in the further lifetime of the ice cloud, causing persistent high ice supersaturation. The values for maximum ice crystal number concentrations for these two cases were $N_{i} \sim 0.025 \mathrm{~cm}^{-3}$ (constant updraught alone, blue line) and $N_{i} \sim 0.048 \mathrm{~cm}^{-3}$ (constant updraught plus wave, red line). Thus, there was a slight enhancement by a factor of about two.

In summary, both the slow and fast motion scenarios showed enhanced ice crystal number concentrations when a short wave was superimposed on the constant updraught. However, slowing down the constant updraught significantly reduced the enhancement of ice crystal number concentrations induced by the short wave. This is the central finding, causing the main effect in our investigations. We will discuss the relevance of such an idealized case for the situation in the TTL in the next section.

Last but not least, it should be noted that for low-frequency waves (e.g. $\omega<0.005 \mathrm{~s}^{-1}$ ) there was no significant difference in simulations with superimposed waves for different large-scale updraughts. This behaviour was already found for small temperature amplitudes $A_{\mathrm{T}} \sim 0.25 \mathrm{~K}$. In all cases, the nucleation event was not stopped by dynamics but by diffusional growth leading to much higher ice crystal number concentrations. The difference in the ice crystal number concentrations was due to the randomly occurring phase of the wave, as already mentioned in previous studies (see e.g. Lin et al., 1998).

\section{TTL dynamics}

In this section, we will look at the different types of vertical motion in the TTL, as driven by very different processes. In the first part, we will explore the large-scale components mainly driven by Kelvin waves, whereas in the second part we will evaluate the conditions in the TTL favouring a special kind of gravity wave.

\subsection{Large-scale dynamics}

First, we will pose the question of whether low vertical updraughts are common in the TTL, especially in the vertical velocity range $|w| \leq 0.01 \mathrm{~m} \mathrm{~s}^{-1}$. There are two different sources for large-scale updraughts in the TTL. The first involves ascents to compensate diabatic heating (e.g. Salby and Callaghan, 2004; Fueglistaler et al., 2009b); this compensating effect led to very small updraughts with vertical velocity values of $w \sim 0.001 \mathrm{~m} \mathrm{~s}^{-1}$. The second source involves large-scale equatorial waves, e.g. Kelvin waves (Webster, 1972; Gill, 1980; Wheeler et al., 2000; Ryu and Lee, 2010; Thompson et al., 2011), which are usually triggered by convection and organized convective systems. Equatorial Kelvin waves with time periods in the order of a few days lead to temperature anomalies of up to $8 \mathrm{~K}$ with typical values around 2-3 K (Immler et al., 2008), which translate into 

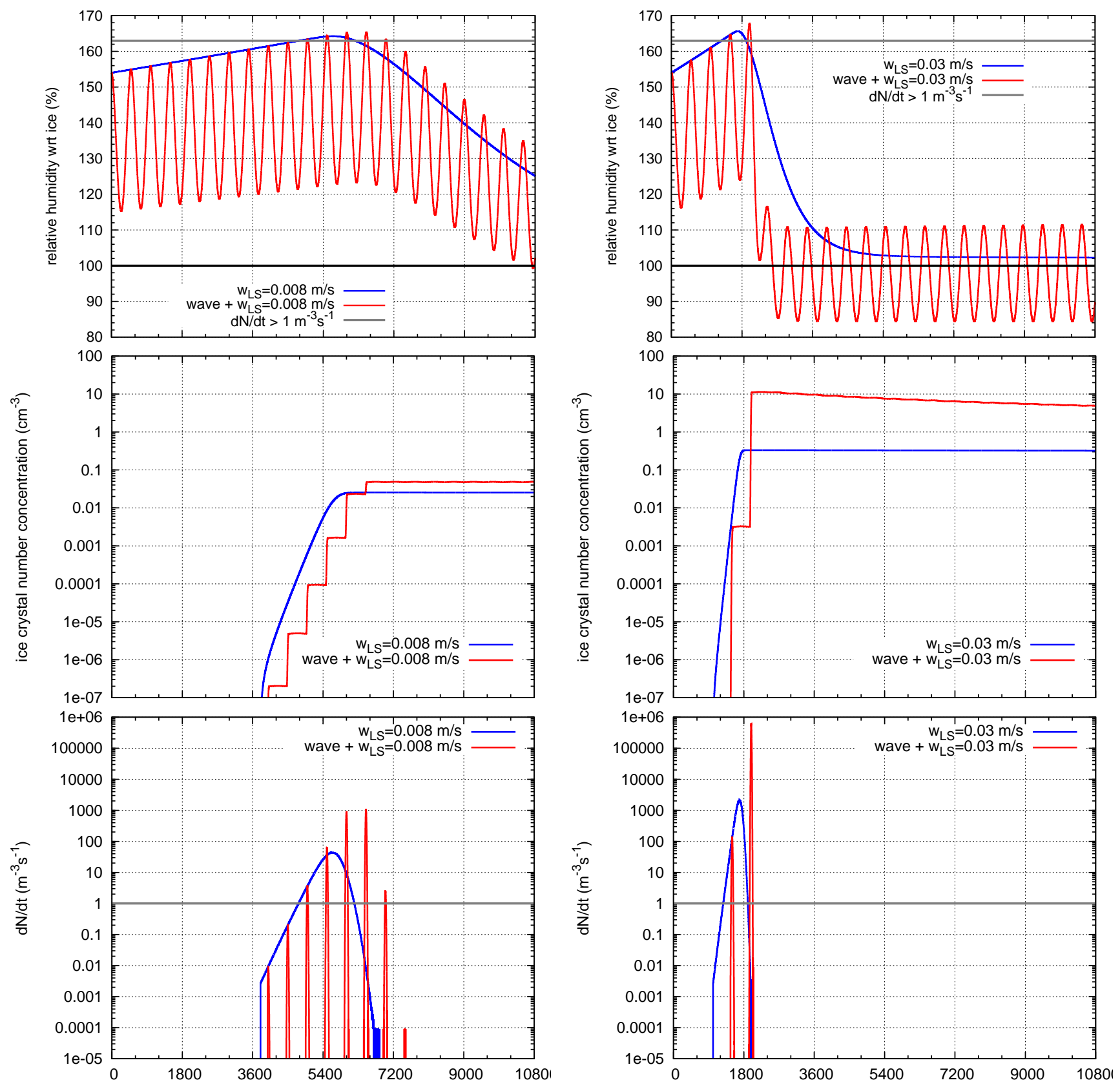

Fig. 4. Examples of cases of updraught scenarios. Left column: large-scale updraught $w_{\mathrm{LS}}=0.008 \mathrm{~ms}^{-1}$ (slow regime), right column: large-scale updraught $w_{\mathrm{LS}}=0.03 \mathrm{~m} \mathrm{~s}^{-1}$ (fast regime). Blue lines indicate constant updraught, red lines denote superposition of large-scale updraught and a short wave. Upper panel: time evolution of the relative humidity with respect to (wrt) ice (in \%); saturation is indicated by a black line, the grey line indicates relative humidity values where the ice crystal concentration rate $\mathrm{d} N / \mathrm{d} t$ exceeds the value $1 \mathrm{~m}^{-3} \mathrm{~s}^{-1}$. Middle panel: time evolution of ice crystal number concentration. Lower panel: time evolution of ice crystal production rate $\mathrm{d} N / \mathrm{d} t$; the value $1 \mathrm{~m}^{-3} \mathrm{~s}^{-1}$ is indicated by a grey line. Here, the stepwise character of the nucleation for the superimposed short wave (red line) can be seen in contrast to the continuous nucleation during a constant large-scale updraught (blue line).

updraughts in the order of $0.002 \leq w_{\mathrm{LS}} \leq 0.01 \mathrm{~m} \mathrm{~s}^{-1}$. There is now evidence from several studies (Boehm and Verlinde, 2000; Immler et al., 2008; Fujiwara et al., 2009; Virts et al., 2010; Flury et al., 2012) that there is a correlation between cold anomalies in the TTL and cirrus clouds. From recent studies on cirrus clouds in the TTL using the lidar in space onboard CALIPSO (Cloud-Aerosol Lidar and Infrared Pathfinder Satellite Observation), the vertical motions in the regions of cirrus cloud occurrence were estimated (Virts et al., 2010). Here, values of the large-scale motion at $p=$ 
$100 \mathrm{hPa}$ were estimated to be in the range $-0.0175 \mathrm{Pas}^{-1} \leq$ $\omega \leq 0$ (see fig. 8.8 in Virts, 2009), which translates into vertical velocities in the range $0 \leq w \leq 0.01 \mathrm{~m} \mathrm{~s}^{-1}$. Thus, from observational and theoretical considerations, the occurrence of low large-scale motions in the range $0 \leq w \leq 0.01 \mathrm{~m} \mathrm{~s}^{-1}$ can be confirmed and the occurrence of cirrus clouds in such updraught regions is quite common. It should be mentioned here that in case of large-scale updraughts in the range $0 \leq w \leq 0.01 \mathrm{~m} \mathrm{~s}^{-1}$ without any superposition of motions on smaller scales, only small ice crystal number concentrations $\left(N_{i} \leq 0.1 \mathrm{~cm}^{-3}\right)$ would occur, as can be derived in Fig. 2 . Additionally, it seems that large-scale motions with vertical velocities of $w>0.01 \mathrm{~m} \mathrm{~s}^{-1}$ are quite rare. This will be important in the following discussion.

In our simulations (see Sect. 5) we will always assume that vertical motions are consistent with adiabatic changes leading to temperature variations. Strictly speaking, this is only true for the second component (Kelvin waves), whereas the diabatic heating compensating would be associated with a lapse rate $\frac{\mathrm{d} T}{\mathrm{~d} z}>-\Gamma$, leading to smaller cooling rates. Since the vertical velocity driven by diabatic heating effects is usually much smaller than the component driven by Kelvin waves, we can neglect this contribution and assume adiabatic changes to a very good approximation.

\subsection{Gravity waves}

In contrast to the (tropical) troposphere, the TTL is much more stable and its dynamics are less vigorous. Convection only very rarely reaches the TTL, exciting gravity waves at its lower boundary by triggering internal gravity waves in the stable stratified layers above the convective cells (Fritts and Alexander, 2003). Additionally, gravity waves are excited at lateral boundaries of the convective updraught regions in order to balance subsidence (Bretherton and Smolarkiewicz, 1989). The stratification of the TTL is very high $(0.01 \leq$ $N \leq 0.025 \mathrm{~s}^{-1}$ ). Figure 5 shows a climatological vertical profile of the potential temperature (left) and the Brunt-Väisälä frequency (right), as derived from SHADOZ measurements (Thompson et al., 2003). The TTL should be full of gravity waves (see, e.g. Fritts and Alexander, 2003; Jensen and Pfister, 2004), although measurements are complicated and usually cover only larger wavelengths, i.e. low-frequency waves. The frequency of gravity waves depends on the thermal stratification as well as on their horizontal and vertical propagation. Recent high-resolution measurements at latitudes $\sim 26^{\circ} \mathrm{N}$ (Wang et al., 2006) support the occurrence of such short high-frequency, mostly horizontally propagating waves. From Lagrangian stratospheric balloon measurements there is also evidence that these high frequency waves really exist in the tropical tropopause layer; actually, they are very pronounced over regions with high convective activity (Vial et al., 2001; Hertzog and Vial, 2001). Thus, our assumption of high-frequency gravity waves in the TTL is quite realistic. For almost horizontally propagating waves, the hor-
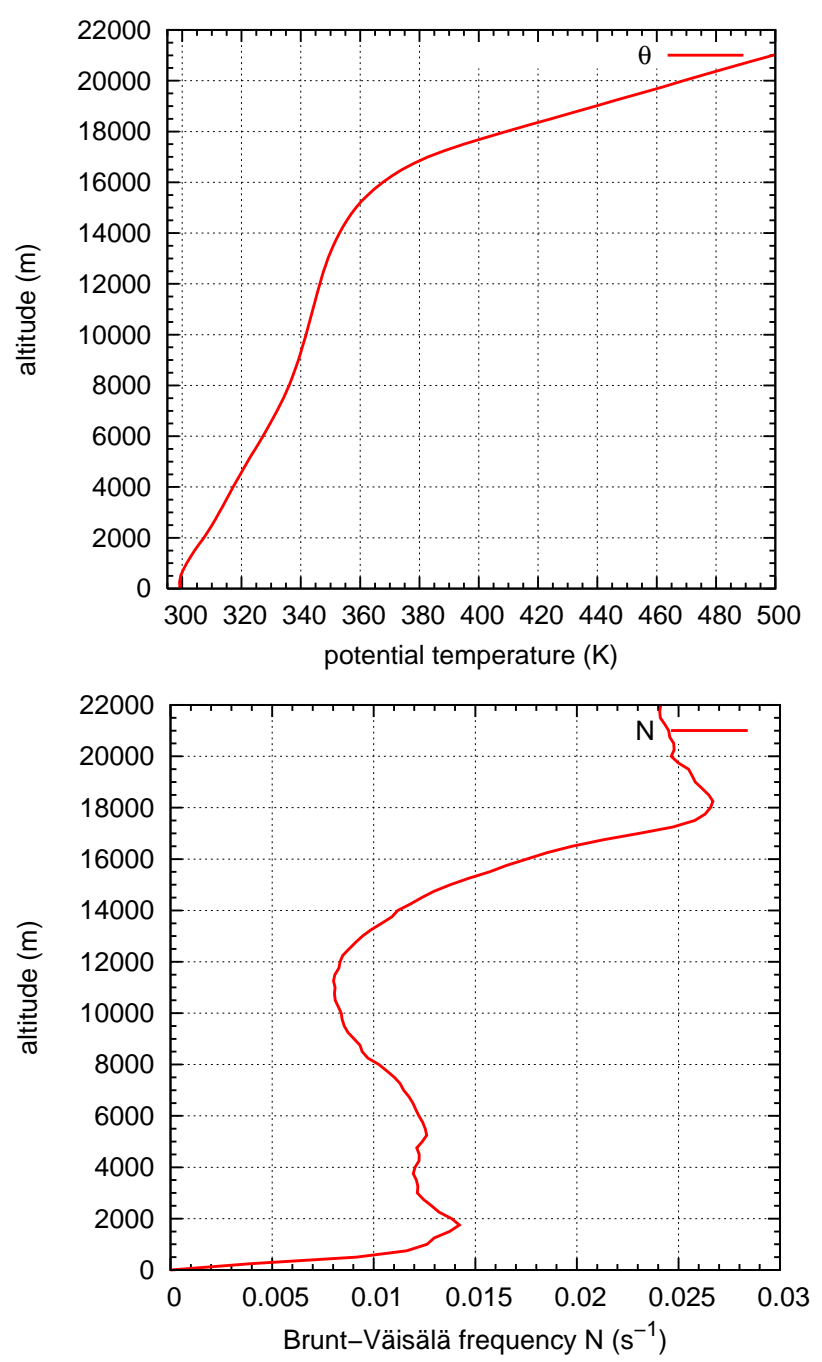

Fig. 5. Mean climatological vertical profiles in the tropical atmosphere as derived from measurements (Thompson et al., 2003); top: potential temperature, bottom: Brunt-Väisälä frequency.

izontal wavelengths can be estimated using $\lambda_{x}=2 \pi U / N$, where $U$ is horizontal wind. Since the mean horizontal wind is quite low (i.e. $U \leq 12 \mathrm{~ms}^{-1}$ ) in the equatorial region (Fueglistaler et al., 2009a), this leads to very small horizontal wavelengths in the order of $3 \mathrm{~km} \leq \lambda_{x} \leq 7.6 \mathrm{~km}$ or roughly $\lambda_{x}<10 \mathrm{~km}$, which are difficult to see from both in situ and from satellite instruments. Thus, we can assume that some of these waves have very high internal frequencies. Typical vertical amplitudes of these waves have been estimated to be in the range $\Delta z \sim 100 \mathrm{~m}$ or even much smaller (Gary, 2006; Gierens et al., 2007), which translates roughly into temperature changes of $\Delta T \leq 1 \mathrm{~K}$. These waves represent the prototype for TTL gravity waves in our investigations. In addition to the boundary conditions from thermal stratification and winds in the TTL, we added more information about a possible restriction of the frequency spectrum in gravity waves 
occurring. From recent theoretical investigations (Ruprecht et al., 2010; Ruprecht and Klein, 2011) on the propagation in the gravity waves in a convectively dominated environment, we know that the full spectrum of frequencies, i.e. $0 \leq \omega \leq N$, does not occur. The convective towers act as high-pass filters, depending on the fractional coverage of the convective cells compared to the cloud-free environment, allowing only part of the frequency to occur. The frequency spectrum is then given by $f \cdot N \leq \omega \leq N$, where $f$ depends on the fractional coverage $\sigma$, i.e. $f \approx \sqrt{\sigma}$. For typical values of $\sigma \sim 0.1$, we get a frequency cut-off factor of $f \approx 0.32$. Since there is a lot of convective activity in the tropical regions, we can assume higher fractional coverage of convective cells. Thus, $\sigma=0.1$ is a lower limit. In later applications of this "frequency window", we will use a lower limit of $f=0.4$, i.e. $f$ will be in the range $0.4 \leq f \leq 1$, corresponding to cloud cover values of $\sim 0.16 \leq \sigma \leq 1$. Unfortunately, there are no direct in situ observations of vertical velocity, thus we cannot compare our dynamical set-up and results with measurements.

\section{Realistic TTL ice cloud simulations}

After observations and theoretical investigations have shown that the conditions as specified in Sect. 3 may occur in the TTL, we will now define more realistic scenarios for a large number of box model simulations. The results of these simulations will be presented in terms of ice crystal number concentrations. Additionally, we will discuss the plausibility of heterogeneous ice nucleation for the situation in the TTL.

\subsection{Model set-up}

For the realistic model simulations, we ran the ice cloud box model along idealized air mass trajectories. The set-up for the microphysics as well as for the idealized dynamics, i.e. trajectories, is described in the next two subsections.

\subsubsection{Model set-up for microphysics}

For a realistic description of the background aerosol conditions in the TTL, we used the output of a 2-D aerosol model (Weisenstein et al., 2007) to calculate size distributions of sulfate aerosols at different pressure levels typical for the TTL ( $p \sim 70 / 100 / 120 / 150 \mathrm{hPa}$ ). The size distributions were fitted with three size modes using lognormal distributions. The fits are shown in Fig. 6, representing the initial size distributions of the sulfuric acid background aerosol. The three size modes of aerosols led to three classes of ice, formed by homogeneous nucleation. The total background aerosol number concentration was of the order $N_{\mathrm{a}} \sim 50-80 \mathrm{~cm}^{-3}$, which agrees well with measurements. However, these values are smaller than the typical aerosol concentrations in the extratropical tropopause region $\left(N_{\mathrm{a}} \sim 300 \mathrm{~cm}^{-3}\right)$. For the environmental conditions in the TTL, we derived the initial tem-

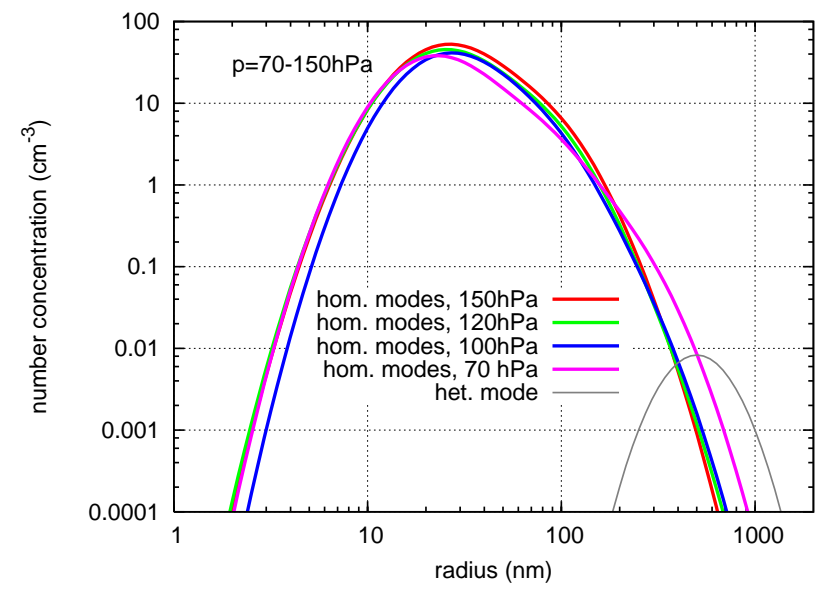

Fig. 6. Initial size distributions of sulfuric acid droplets in the TTL for the pressure levels 70/100/120/150 hPa (colour code indicated in the inset legend), as derived from a 2-D aerosol model (Weisenstein et al., 2007); additionally, the size distribution of the heterogeneous ice nuclei as used for heterogeneous nucleation is indicated (grey line).

perature/pressure from the climatological values (see Fig. 5) and the spread in the measurements (see, e.g. Thompson et al., 2003; Fueglistaler et al., 2009a; Selkirk et al., 2010). The values are given in Table 1. Note that the initial temperatures were set about $10 \mathrm{~K}$ lower than the mean climatological values shown in Fig. 5. We shifted the temperature profile in order to be consistent with the in situ measurements (Krämer et al., 2009) as otherwise the temperatures in our simulations would have been too high. The pressure/temperature conditions are then in good agreement with the measurements (Schiller et al., 2008; Krämer et al., 2009).

We wanted to investigate ice nucleation at specific environmental conditions typical of the TTL (temperature/pressure) as given by values in Table 1 . Thus, the model initialization was specified to ensure that ice nucleation starts near the given values at around half the simulation time (i.e. after $\sim 5 \mathrm{~h}$ ) in the case of a pure large-scale updraught. For example, when $T_{\text {nuc }}=196 \mathrm{~K}$ and $p_{\text {nuc }}=150 \mathrm{hPa}$ with a constant updraught of $w_{\mathrm{LS}}=0.01 \mathrm{~ms}^{-1}$, we set $T_{\text {init }}=$ $197.8 \mathrm{~K}$ and $p_{\text {init }}=154.78 \mathrm{hPa}$. Using this procedure, we ensured that when high-frequency waves with high amplitudes were superimposed to the large-scale updraught (see Sect. 5.1.2) nucleation would occur close to the typical temperature/pressure values.

The box model also included a module for the sedimentation of ice crystals (Spichtinger and Cziczo, 2010). To activate this module, additional information on the vertical extension of the box $\Delta z$ as well as on the sedimentation factor $f_{\text {sed }}$ was required. Here, we specified $\Delta z=200 \mathrm{~m}$, $f_{\text {sed }}=0.5$ in the upper part of the cloud (i.e. the main nucleation zone) and $f_{\text {sed }}=0.9$ in the middle part of the cloud (see discussion in Spichtinger and Cziczo, 2010). The thickness 
Table 1. Settings for realistic simulations to be fulfilled at ice nucleation.

\begin{tabular}{lcccc}
\hline$p(\mathrm{hPa})$ & 70 & 100 & 120 & 150 \\
\hline$T(\mathrm{~K})$ & 190 & 184 & 188 & 196 \\
\hline$N_{\max }\left(\mathrm{s}^{-1}\right)$ & 0.029 & 0.022 & 0.0172 & 0.0128 \\
$N_{\operatorname{mean}}=N_{\max } \cdot 0.9\left(\mathrm{~s}^{-1}\right)$ & 0.0261 & 0.0198 & 0.0155 & 0.0115 \\
$N_{\min }=N_{\max } \cdot 0.4\left(\mathrm{~s}^{-1}\right)$ & 0.0116 & 0.0088 & 0.0069 & 0.0051 \\
\hline
\end{tabular}

of the cloud layers are based on recent measurements by Jensen et al. (2013), indicating layers with a vertical extension in the order of $O(100-500 \mathrm{~m})$.

\subsubsection{Model set-up for dynamics}

We saw in Sect. 4 that the TTL dynamics were dominated by motions on two different scales, namely (a) very low largescale updraughts in the order of $w_{\mathrm{LS}} \leq 1 \mathrm{~cm} \mathrm{~s}^{-1}$ and (b) highfrequency gravity waves triggered by convective activity. The large-scale updraughts were triggered by large-scale features such as Kelvin waves, occupying large horizontal regions in the tropical atmosphere. Thus, gravity waves are embedded into the slowly lifted environment. In terms of an ascending air parcel along a trajectory, we thus assumed a slowly lifted parcel, which also experiences a superimposed (highfrequency) oscillation driven by gravity waves. As described above, the source for the gravity waves is most likely convection. Either waves are triggered by convective plumes bouncing against the TTL from below or waves are radiated laterally from the convective tower. In both cases, we can assume intrinsic gravity waves with frequencies near the thermal stratification of the TTL (i.e. $\omega \approx N$ ). Thus, in our simulations we concentrated on monochromatic waves with a distinct frequency as determined below. For our box model calculations we specified - similar to the idealized simulations in Sect. 3 - a vertical velocity for lifting the (closed) air parcel adiabatically as a superposition of the two motions mentioned above: $w(t)=w_{\mathrm{LS}}+w_{\text {wave }}(t)$, i.e. expressed as vertical velocities, which are more natural in a dynamical point of view. For the large-scale component $w_{\text {LS }}$ we then specified the following ranges, split into a very slow and a faster velocity range:

$$
w_{\mathrm{LS}}=\underbrace{0.003 / 0.005 / 0.008 / 0.01}_{\text {very slow }} / \underbrace{0.02 / 0.03 / 0.05}_{\text {faster }} \mathrm{m} \mathrm{s}^{-1} \text {. }
$$

Hence, to determine the monochromatic wave component $w_{\text {wave }}(t)$, we use again temperature changes $\left(T(t)=T_{\text {init }}+\right.$ $\left.T_{\mathrm{LS}}(t)+T_{\text {wave }}(t)\right)$ instead of changes in the vertical velocity; this approach is also due to observational constraints on the amplitude of temperature variations in the TTL. We assumed an adiabatic process; i.e. that the vertical velocity was connected to temperature changes via Eq. (5). Thus, the temperature driven by this motion is given by Eq. (7) with $A_{\mathrm{T}}$ as amplitude of the temperature variation. From observations, we know that the amplitude can reach values up to $A_{\mathrm{T}}=1 \mathrm{~K}$, thus we specified the range $A_{\mathrm{T}}=0.1 / 0.25 / 0.5 / 0.75 / 1.0 \mathrm{~K}$. As stated for the large-scale component, the value of $A_{\mathrm{T}}$ was fixed for one simulation. From Ruprecht et al. (2010) (see Sect. 4), we know that the frequency spectrum is bounded by the Brunt-Väisälä frequency $N$ and a lower value $f \cdot N$, where $f$ depends on the area covered by convective cells, i.e. on the fraction $\sigma$. By assuming a typical lower limit of $\sigma \leq 0.1$, we set the range for the real frequency of the waves, $\omega=f \cdot N, f=0.4 / 0.5 / 0.6 / 0.7 / 0.8 / 0.9 / 1$; as stated for the other parameters, $f$ and $N$ were fixed for a whole single simulation. To specify the typical Brunt-Väisälä frequency, we used the climatological mean derived from Fig. 5. In order to investigate a realistic range of frequency spectra, we set the maximum value $N_{\max }$ (as given in Table 1) so that the mean climatological value $N_{\text {mean }}$ was approximately given by $N_{\text {mean }} \approx 0.9 \cdot N_{\max }$. Consequently, the lower limit of the frequency window is given by $N_{\min }=0.4 \cdot N_{\max }$. The range of frequencies for the different pressure levels is shown in Fig. 7. In the Appendix, the amplitudes $A_{\mathrm{W}}$ are reported for different values of $N_{\max }$ and $f$, respectively. In summary, we ran single box model simulations with a superposition of a constant large-scale component and one monochromatic wave so that the temperature evolution of a single run was

$T(t)=T_{\text {init }} \underbrace{-\Gamma \cdot w_{\mathrm{LS}} \cdot t}_{\text {large scale }} \underbrace{+A_{\mathrm{T}} \cos \left(f \cdot N_{\max } \cdot t\right)}_{\text {wave }}$.

This equation is consistent with a representation of the vertical velocity components as derived earlier in Sect. 3.1. In our simulations, we used all possible combinations as stated above plus simulations with large-scale updraughts only, i.e. $A_{\mathrm{T}}=f=0$. The total simulation time for each single case was $t_{\mathrm{sim}}=36000 \mathrm{~s}(10 \mathrm{~h})$ with a time step of $\Delta t=0.1 \mathrm{~s}$ in order to resolve nucleation events as best as possible (see discussion in Spichtinger and Gierens, 2009a). As described below, two scenarios for the nucleation were chosen, namely (1) pure homogeneous nucleation and (2) heterogeneous and possibly homogeneous nucleation within the same environment. In summary, we ended up with 4032 simulations.

For a statistical investigation, we collected values from all simulations, filtered by a certain criterion (e.g. slow vs. fast large-scale component or pure homogeneous nucleation vs. homogeneous and heterogeneous nucleation).

\subsection{TTL ice crystal numbers from homogeneous nucleation}

Figure 8 shows the frequencies of occurrence of ice crystal number concentrations derived from all simulations with homogeneous ice nucleation (HOM) described in the previous section together with the in situ measurements from Krämer 


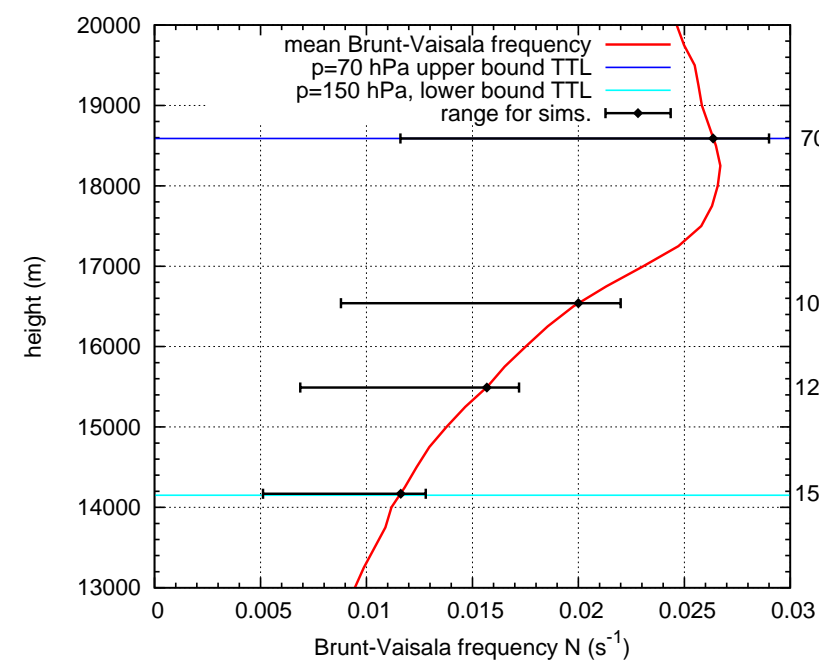

Fig. 7. Vertical profile of static stability (mean Brunt-Väisälä frequency) as derived from measurements (Thompson et al., 2003). Additionally, the range for the initialization of the simulations is indicated by horizontal black bars, where we set $N_{\text {mean }} \approx 0.9 \cdot N_{\max }$ (red line and black dots); thus, the bars show the interval 0.4 . $N_{\max } \leq N \leq N_{\max }$ as described in detail in Sect. 5.1; the values of $N_{\max }, N_{\text {mean }}$ and $N_{\min }=0.4 \cdot N_{\max }$, respectively, are reported in Table 1.

et al. (2009). The results are split into simulations with superimposed very slow large-scale motion $\left(w_{\mathrm{LS}} \leq 1 \mathrm{cms}^{-1}\right.$, green) and simulations with superimposed faster large-scale motion ( $w_{\mathrm{LS}}>1 \mathrm{~cm} \mathrm{~s}^{-1}$, blue). The observations were surprisingly well represented by the simulations with very slow $w_{\mathrm{LS}}$, although the set-up was not tuned for this purpose. Ice crystal number concentrations from the simulations were in the range $0.001 \leq N_{i} \leq 0.3 \mathrm{~cm}^{-3}$ (note that the detection limit of the measurements was about $0.005 \mathrm{~cm}^{-3}$; lower concentrations from the simulations were clipped for better comparison; the effect on the resulting $N_{i}$ frequency distribution is negligible). However, the peak in the measurements around $N_{i} \sim 0.005-0.007 \mathrm{~cm}^{-3}$ was missing in the simulations and the higher observation values were not reached. Nevertheless, the shape of the frequency distribution in the range $0.01 \leq N_{i} \leq 0.3 \mathrm{~cm}^{-3}$ was almost perfectly matched.

In contrast to the simulations for very slow large-scale velocities, the measurements were not reproduced by faster large-scale vertical motions. In these simulations, the probability density function (pdf) of ice crystal number concentration had a similar shape as the very slow $w_{\text {LS }}$ pdf. However, the distribution shifted to very high values of $N_{i}$. The broad peak of the pdf was in the range $0.5 \leq N_{i} \leq 5 \mathrm{~cm}^{-3}$ with quite frequent values up to $N_{i} \sim 20 \mathrm{~cm}^{-3}$. The pdf compares well to that shown by Jensen et al. (2010, their fig. 6), though in the study of Jensen et al. (2010) the peak and maximum ice concentrations were smaller, likely because a large-scale motion of $0.3 \mathrm{~cm} \mathrm{~s}^{-1}$ (superimposed with a broad

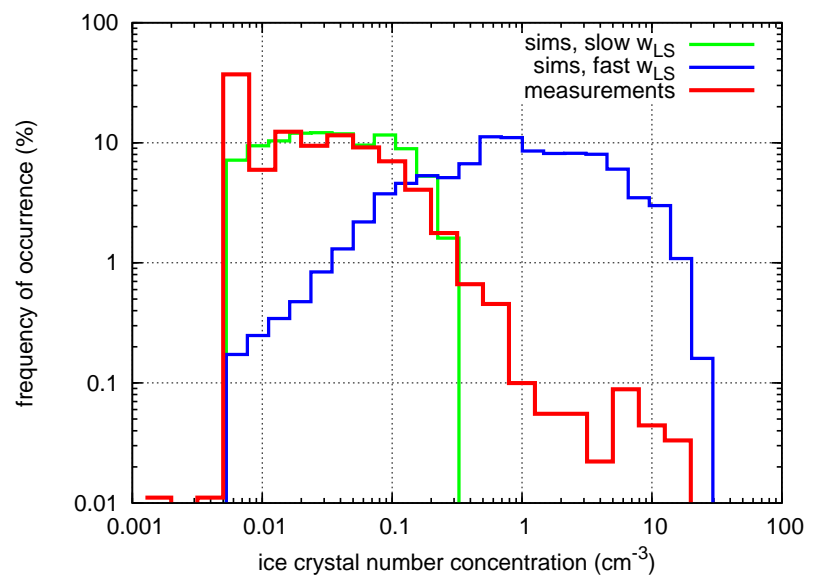

Fig. 8. Frequencies of occurrence of ice crystal number concentrations from simulations with pure homogeneous freezing in very slow and faster large-scale motions $\left(w_{\mathrm{LS}} \leq 1 \mathrm{~cm} \mathrm{~s}^{-1}\right.$, green; $w_{\mathrm{LS}}>$ $1 \mathrm{~cm} \mathrm{~s}^{-1}$, blue); the red line represents the measurements of Krämer et al. (2009). Note that the detection limit of the measurements is $N_{i} \sim 0.005 \mathrm{~cm}^{-3}$; thus, the lowest concentration bins of the model simulations are clipped for better comparison with the measurements.

spectrum of gravity waves) was used, which ranges here up to $0.5 \mathrm{~cm} \mathrm{~s}^{-1}$. From the comparison of pdfs from very slow and faster large-scale updraughts, we see that the transition from low to high number concentrations in the case of highfrequency waves is determined by the large-scale component of the vertical velocity. There is a clear separation between these different regimes, and the critical values seem to be around $w \sim 1 \mathrm{~cm} \mathrm{~s}^{-1}$.

Additionally, it should be noted that in both sets of simulations very high vertical velocities up to values of $w \sim 3 \mathrm{~m} \mathrm{~s}^{-1}$ occurred. The statistics for vertical velocities in the different regimes (very slow vs. faster $w_{\mathrm{LS}}$ ) are shown in Fig. 9. It can be seen from the figure that the vertical velocity distributions are almost identical except for a "shift" of about $\Delta w \sim 0.03 \mathrm{~m} \mathrm{~s}^{-1}$, given by the large-scale component. However, the ice crystal number concentrations were decoupled from the vertical velocities, since the nucleation events in high frequency waves were stopped by downdraughts (see Sects. 2 and 3) and not by diffusional growth. Thus, it makes no sense anymore to evaluate the vertical velocity to estimate ice crystal number concentrations as the simple 1-1 relationship shown e.g. in Fig. 2. This is an important issue, since many theoretical investigations are based on this correspondence between vertical velocity and ice crystal number concentration (e.g. Hoyle et al., 2005), but in our case of a highly variable environment, this relationship is not valid anymore. 


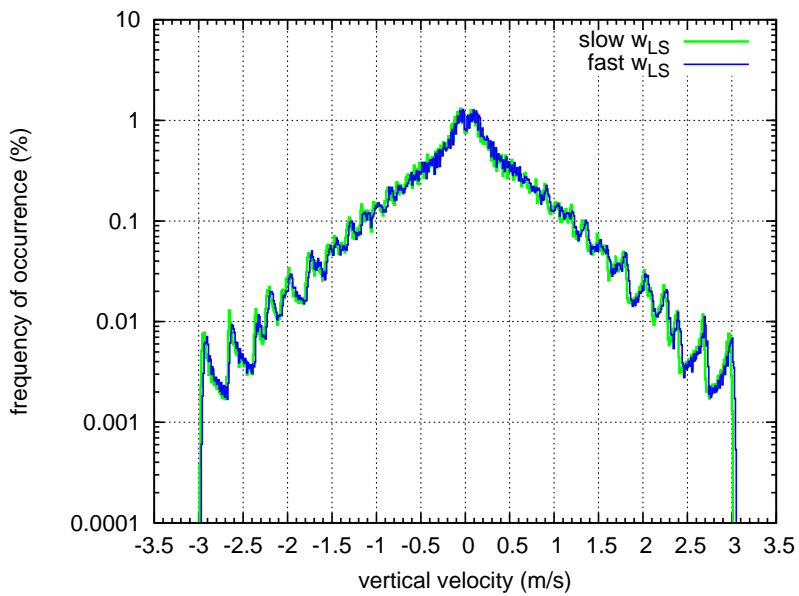

Fig. 9. Vertical velocity from simulations with pure homogeneous freezing in very slow $\left(w_{\mathrm{LS}} \leq 1 \mathrm{cms}^{-1}\right.$, green $)$ and faster $\left(w_{\mathrm{LS}}>\right.$ $1 \mathrm{cms}^{-1}$, blue) large-scale motions. The absolute values and the distributions are nearly equal, except for the shift of about $\Delta w \sim$ $0.03 \mathrm{~m} \mathrm{~s}^{-1}$, given by the large-scale vertical velocity $w_{\mathrm{LS}}$.

\subsection{TTL ice crystal numbers from heterogeneous and homogeneous nucleation}

Heterogeneous nucleation was brought into the discussion to explain the low ice crystal number concentrations in the TTL (Khvorostyanov et al., 2006; Gensch et al., 2008; Krämer et al., 2009; Jensen et al., 2008, 2010; Murray et al., 2010). Thus, we extended our simulations by including heterogeneous nucleation in the following way: we added another class of ice representing heterogeneous nucleation on solid particles, although we did not specify the nature of the ice nuclei (IN) but merely the effect of freezing ice crystals on them. One could think of these IN as a mixture of glassy particles (Murray et al., 2010), crystallized ammonium sulfate particles (Jensen et al., 2010) and mineral dust (Froyd et al., 2009), which are all possible candidates causing heterogeneous freezing in the TTL. In Fig. 6, the additional heterogeneous IN mode is indicated by the grey curve. Here, we again use a lognormally distributed aerosol with modal diameter $L_{\mathrm{m}}=0.5 \mu \mathrm{m}$, a geometrical standard deviation of $\sigma_{\mathrm{L}}=1.4$ and a total number concentration of $N_{\mathrm{IN}}=7 \mathrm{~L}^{-1}$ (see e.g. DeMott et al., 2003). The nucleation threshold is size-dependent, i.e. $\mathrm{RHi}_{\text {het }}=(a / L)^{b}+\mathrm{RHi}_{0}$ (Spichtinger and Cziczo, 2010), with $a=1 \mu \mathrm{m}, b=0.65$, and $\mathrm{RHi}_{0}=$ $143.5 \%$; thus, the thresholds are quite high (in the order of RHi 145\%), mimicking quite bad IN (i.e. inefficient freezing properties). We chose this option because good IN should be washed out by freezing and sedimentation at lower altitudes, while only bad IN will survive the transport to higher altitudes in the TTL. We then ran the same set of simulations as described in Sect. 5.1 with additional heterogeneous freezing. Note that when the homogeneous freezing threshold was reached after heterogeneous ice nucleation, a second (homo-

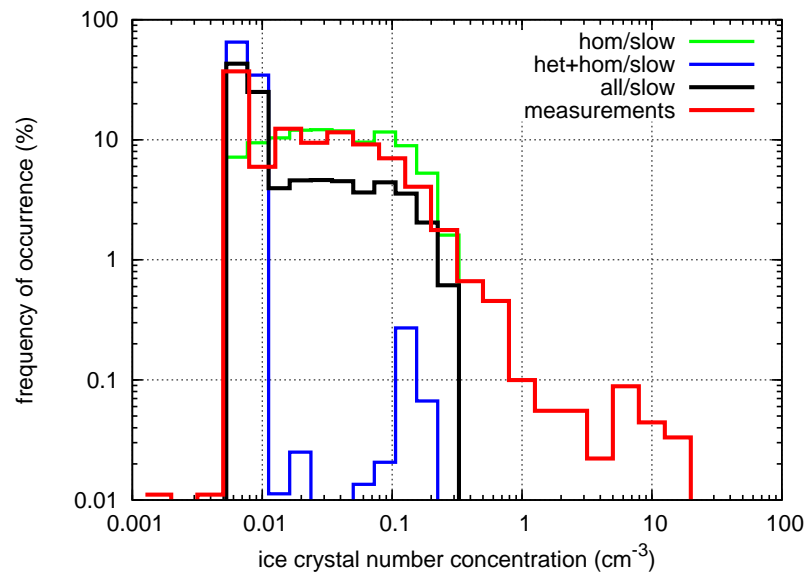

Fig. 10. Frequencies of occurrence of ice crystal number concentrations from simulations in very slow large-scale motions $\left(w_{\mathrm{LS}} \leq 1 \mathrm{cms}^{-1}\right)$ with homogeneous freezing (hom, green), heterogeneous+homogeneous freezing (het+hom, blue) and a mixture of both (all, black); the red line represents the measurements of Krämer et al. (2009). Note that the lowest concentration bins of the model simulations are clipped for better comparison with the measurements.

geneous) freezing event occurred in the simulations. The heterogeneous INs could stem (classically) from advected mineral dust or even from glassy particles, as proposed by Murray et al. (2010), in our parameterization we just included the freezing effect but not the nature of the INs.

In Fig. 10, the results for superimposed very slow largescale motions are shown for pure homogeneous nucleation (hom, same green line as in Fig. 8) and for competing heterogeneous-homogeneous nucleation (het+hom, blue curve) as described above. For a better comparison, Fig. 10 also shows the sum of all simulations (all: hom+het/hom, black curve) and the in situ measurements (red curve). The most remarkable feature of competing heterogeneous nucleation can be seen in the blue pdf: heterogeneous freezing formed ice crystals before homogeneous nucleation was triggered. Thus, few ice crystals (in order of $N_{i} \sim 7 \mathrm{~L}^{-1}$, see peak in Fig. 10) grew in a highly supersaturated environment depleting water vapour in a considerable way. Additional homogeneous nucleation events were rare and produced the ice crystal numbers between $N_{i} \sim 0.01-0.1 \mathrm{~cm}^{-3}$, or nucleation was quenched (see discussion in Spichtinger and Gierens, 2009a, b; Spichtinger and Cziczo, 2010). This led to a general reduction of the ice crystal number concentrations, which can be seen in the pdf (Fig. 10, blue curve). For simulations with waves superimposed on faster large-scale components there was almost no effect compared to pure homogeneous nucleation (not shown). It is also remarkable that the peak in the measurements at $N_{i} \sim 0.005$ $0.008 \mathrm{~cm}^{-3}$ (red curve) was reproduced by heterogeneous ice nucleation. To sum up all simulations (black curve), there 
Table 2. Numbering for the different pdfs of scenarios as follows: hom,slow: pure homogeneous nucleation for slow vertical updraughts, hom,fast: pure homogeneous nucleation for faster vertical updraughts, het+hom, slow: heterogeneous+homogeneous nucleation for slow vertical updraughts, hom/het+hom,fast: pure homogeneous and heterogeneous+homogeneous nucleation for fast vertical updraughts.

\begin{tabular}{ccccc}
\hline index & 1 & 2 & 3 & 4 \\
\hline scenario & hom,slow & hom,fast & het+hom,slow & hom/het+hom,fast \\
\hline
\end{tabular}

is an agreement with the observations, although part of the ice events in the concentration range $N_{i} \sim 0.01-0.3 \mathrm{~cm}^{-3}$ are missing and the events at $N_{i}>0.3 \mathrm{~cm}^{-3}$ are not represented by the model simulations.

Seemingly, both pure homogeneous freezing events and heterogeneous+homogeneous ice formation in very slow large-scale motions superimposed with short, high-frequency gravity waves contribute significantly to the TTL ice clouds, but cannot explain the full observed ice crystal concentration spectrum, especially not the rare high ice crystal number concentrations.

Instead, a composition of different scenarios might lead to better agreement with the measurements. From the observations it is quite obvious that events producing low ice number concentrations are more likely than events associated with high ice number concentrations (Fig. 3). Thus, we adapted weighting factors for the different events by using normalized pdfs of the different scenarios, i.e. (1) pure homogeneous nucleation for slow vertical updraughts $f_{1}:=f_{\text {hom,slow }}$, (2) pure homogeneous nucleation for faster vertical updraughts $f_{2}:=f_{\text {hom,fast }}$, (3) heterogeneous+homogeneous nucleation for slow vertical updraughts $f_{3}:=f_{\text {het }+ \text { hom, slow }}$, and (4) pure homogeneous and heterogeneous+homogeneous nucleation for fast vertical updraughts $f_{4}:=f_{\text {hom }}$ het + hom,fast . The selection of these pdfs is motivated by the results of our simulations (see Figs. 8 and 10) showing different behaviours of frequencies of occurrence. We will see later that a careful weighting of these different scenarios will lead to a better but not complete agreement of the simulations with the observations. For brevity, we numbered the different scenarios as described in table 2. We combined these pdfs to form one pdf using weighting coefficients via

$$
f_{\mathrm{comb}}:=\sum_{i=1}^{4} a_{i} f_{i} / \sum_{i=1}^{4} a_{i}
$$

such that the mixture of the scenarios best matched the observations. The weighting coefficients are chosen "by eye" (guided by the shape of the measurement pdf), since to derive an algorithm to calculate the coefficients is very complex and would not necessarily lead to a better result. The components associated with low number concentrations should

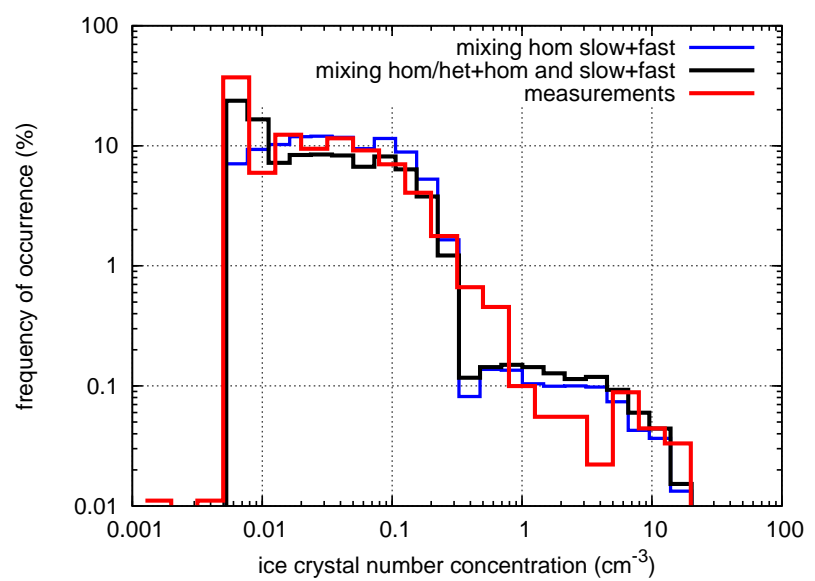

Fig. 11. Frequency of occurrence of ice crystal number concentrations: mixture of simulations in very slow $\left(w_{\mathrm{LS}} \leq 1 \mathrm{cms}^{-1}\right)$ and faster $\left(w_{\mathrm{LS}}>1 \mathrm{~cm} \mathrm{~s}^{-1}\right)$ large-scale motions with homogeneous freezing (hom, blue) and with heterogeneous+homogeneous freezing (hom/het+hom, black); the red line represents the measurements of Krämer et al. (2009); the lowest concentration bins of the model simulations are clipped off for a better comparison with the measurements.

likely dominate the pdfs. Additionally, the peak around $N_{i} \sim$ $0.005-0.008 \mathrm{~cm}^{-3}$ might be represented best by scenarios including heterogeneous nucleation events. On the other hand, scenarios producing high ice crystal number concentrations (i.e. pdfs $f_{2}, f_{4}$ ) should not have a large weight. This is also in agreement with the range of large-scale vertical motions as reported by Virts et al. (2010), which is usually $w \leq 0.01 \mathrm{~m} \mathrm{~s}^{-1}$ (see discussion in Sect. 4.1). The occurrence of a few vertical layers containing very high ice crystal number concentrations in between layers of low number concentrations can be seen clearly in investigations by Jensen et al. (2013). Thus, our choice of a very small weight for the scenarios of fast large-scale motions seems reasonable from this point of view.

Some combinations of the full set of model simulations are shown in Fig. 11. Here, the blue curve represents a mixture of all simulations in the very slow and faster largescale motion regimes with pure homogeneous freezing, using coefficients $a_{1}=0.99, a_{2}=0.01, a_{3}=a_{4}=0$. In this case, it can be seen that the observations were reproduced well for ice concentrations $N_{i}>0.01 \mathrm{~cm}^{-3}$. Only the peak at $N_{i} \sim 0.005-0.008 \mathrm{~cm}^{-3}$ was still missing. However, adding the simulations with heterogeneous+homogeneous ice formation to the mixture (black curve) ensured agreement between model simulations and observations.

The combination of pdfs of the simulated ice concentration frequency spectra best matching the observations showed that the lowest ice crystal numbers $\left(<0.01 \mathrm{~cm}^{-3}\right)$ stemmed most likely from heterogeneous as well as homogeneous freezing in the very slow large-scale updraughts $(\sim 20 \%$, 
i.e. $\left.a_{3}=0.2\right)$, that the middle ice crystal numbers $(0.01-$ $\left.0.3 \mathrm{~cm}^{-3}\right)$ were solely from homogeneous freezing in the same updraught regime $\left(\sim 79 \%\right.$, i.e. $\left.a_{1}=0.79\right)$, and that the highest TTL ice crystal concentrations $\left(>0.3 \mathrm{~cm}^{-3}\right)$ also evolved from homogeneous freezing or even heterogeneous and homogeneous freezing occurring within the same environment, but in the faster large-scale updraughts $(\sim 1 \%$, i.e. $a_{4}=0.01$ ). Consequently, we also set $a_{2}=0$. Hence, about $80 \%$ of the TTL cirrus can be explained by "classical" homogeneous ice nucleation (Koop et al., 2000) and the remaining $20 \%$ by a combination of heterogeneous and homogeneous freezing within the same environment. The mechanism limiting the ice crystal production from homogeneous freezing in an environment full of gravity waves is the shortness of the waves, causing the freezing events to stall before a higher number of ice crystals can be formed. As stated above, the superposition of two different dynamic motion regimes (slow large-scale component and high-frequency waves) is crucial for this kind of mechanism explaining low ice crystal number concentrations.

It might be that from superposition of high-frequency waves nucleation events producing high number concentrations are triggered; thus, the weight for the component $f_{4}$ cannot really be determined, it could be even smaller than $1 \%$. The robust feature, however, is the high frequency of occurrence of scenarios with slow large-scale updraughts in combination with high-frequency waves.

\section{Discussion}

The model study presented here shows that the measured low TTL ice crystal number concentrations can be represented using a realistic set-up for the special dynamics in that region and "classical" homogeneous ice nucleation (e.g. Koop et al., 2000). Additionally, we were able to represent the shape of the ice crystal number frequency distribution in a very reasonable way.

It was found that the ice crystal number densities are bound to the velocity regimes in the TTL. Superimposing the TTL high-frequency short waves with slow large-scale vertical velocities $\left(w_{\mathrm{LS}} \leq 0.01 \mathrm{~m} \mathrm{~s}^{-1}\right)$ yielded the observed low ice crystal number concentrations, since the ice nucleation events were stalled early on by downdraughts. On the other hand, lower frequencies of the short gravity waves or faster large-scale motions $\left(w_{\mathrm{LS}}>0.01 \mathrm{~m} \mathrm{~s}^{-1}\right)$ triggered higher ice crystal number concentrations. These cases reflect what we would expect from theory (Lin et al., 1998; Hoyle et al., 2005 ) and what is usually discussed in studies about the impact of homogeneous nucleation on the TTL ice crystal numbers, concluding that this formation mechanism is unable to produce low ice concentrations (Jensen and Pfister, 2004). The major new part of our study is the special combination of high frequency waves and very slow large-scale updraughts.
Furthermore, we found that the shape of the measured ice crystal frequency distribution can be represented by mixing different possible scenarios: in many cases there were no heterogeneous IN available, and thus pure homogeneous nucleation was the dominant pathway $(\sim 79 \%)$. In some rarer scenarios, heterogeneous nucleation took place in addition to homogeneous nucleation $(\sim 20 \%)$, and finally, sometimes the dynamic conditions also differed, i.e. the more unlikely case of faster large-scale updraughts occurred $(\sim 1 \%)$. Generally, we can state that heterogeneous nucleation is not the main pathway for the formation of very low ice crystal number concentrations, but that the major mechanism is homogeneous ice nucleation driven by the special TTL dynamics; heterogeneous nucleation simply modifies the nucleation events but does not qualitatively change the results.

In many recent studies (see e.g. Murray et al., 2010) the contamination of the sulfuric acid droplets by organics and thus the inhibition of homogeneous nucleation is considered to be the main reason for very low ice crystal number concentrations in the TTL. However, homogeneous nucleation would only be suppressed, if almost all background aerosol droplets were contaminated by these substances. From recent measurements (see e.g. Froyd et al., 2009), we know that there is a significant contribution of organics in the TTL. However, the relative mass fraction of organics in the TTL is never higher than $80 \%$ (e.g. the case of Pre-AVE ${ }^{1}$, where exceptionally high values were measured), and in many measurements, the relative fraction of organics in the TTL is in the range of $0.1-0.5$ (e.g. CR-AVE ${ }^{2}$ cases). Thus, it is very unlikely - at least from real measurements - that organics can suppress homogeneous nucleation completely, since the non-contaminated particles will nucleate to ice crystals.

In former studies on the impact of dynamics, a spectrum of gravity waves was usually used to drive the box models (see e.g. Jensen and Pfister, 2004). Although these spectra were determined from measurements, it is unclear if they are really representative of the TTL conditions and high-frequency waves were not included in these studies. The main reason for neglecting these waves was the lack of measurement techniques capable of detecting these very short wavelengths or equivalently high frequencies. Thus, the effects discussed in this study were not included in former studies. As we pointed out in our discussion, the short wavelengths (i.e. high frequencies $\omega>0.005 \mathrm{~s}^{-1}$ ) are extremely important for very short freezing events. For longer wavelengths (i.e. low frequencies $\omega<0.005 \mathrm{~s}^{-1}$ ), as used in former studies, the impact of dynamics increases significantly the ice crystal number concentrations.

In our study, we concentrated on monochromatic waves, which is a reasonable restriction. However, if we were to assume a spectrum of superimposed waves within the narrow spectral window as indicated by the theoretical

\footnotetext{
${ }^{1}$ Pre-Aura Validation Experiment, 2004

${ }^{2}$ Costa Rica Aura Validation Experiment, 2006
} 
considerations (Ruprecht et al., 2010), this might lead to a spread in number concentrations towards larger values. In some sensitivity studies (not shown), the quality of the results driven by monochromatic waves did not change.

In contrast to former studies (see e.g. Jensen and Pfister, 2004; Jensen et al., 2010) the amplitude of the waves was not restricted to very small amplitudes to obtain low ice crystal number concentrations. For our approach this restriction was unnecessary, because the nucleation event was determined by the high frequencies $\left(\omega \in\left[0.005 \mathrm{~s}^{-1}: 0.029 \mathrm{~s}^{-1}\right]\right)$ and not by the amplitude of the waves. Thus, our simulations were more realistic in this sense, because the whole spread of amplitudes in the range up to $\Delta T \sim 1 \mathrm{~K}$ can be observed from measurements (Gary, 2006). Our results are in qualitative agreement with former studies by Barahona and Nenes (2011) for their investigations with temperature amplitudes $\delta T \leq 1 \mathrm{~K}$ although we had a different approach where we used high-frequency waves.

With the box model approach mixing effects cannot be taken into account. Actually, there are two effects which might influence the formation of ice crystals. First, horizontal motions could lead to a spread of formed ice crystals into neighbouring regions where ice nucleation did not occur before. Thus, the spread crystals will then grow in supersaturated but clear air, reducing water vapour such that further ice nucleation is quenched. This effect was already investigated in former studies (Spichtinger and Gierens, 2009b). Second, ice crystals from ice clouds above (e.g. from convective outflow or in situ formed clouds) could sediment into clear air and again quench ice nucleation, as discussed in former studies (Barahona and Nenes, 2011). Both effects would lead to a further reduction of ice crystal number concentrations instead of an enhancement.

We already mentioned the contamination of the background aerosol solution droplets by organic substances. Although the contamination and thus suppression of homogeneous nucleation works well in laboratory experiments (Zobrist et al., 2008; Murray et al., 2010), at the moment there is no indication from in situ measurements in the TTL (a) that the respective substances (e.g. citric acid) are available in the TTL and (b) that there is contamination of almost all aerosol particles in order to guarantee total suppression of homogeneous nucleation (see e.g. discussion in Kärcher and Koop, 2005). The corroboration by measurements is still lacking. On the other hand, contamination of some aerosol particles could lead to additional heterogeneous IN. Since we did not specify the type of heterogeneous INs used in this study, there could be room for such glassy particles.

However, in our opinion, the total suppression of homogeneous nucleation by contamination with the suitable material is the subject of a very complex theory. Our proposal allows classical homogeneous and heterogeneous ice nucleation to occur in a very simple dynamic set-up, given by the special environment of the TTL. Applying Ockham's razor (principle of parsimony) we tend to prefer the simpler dynamic ap- proach, particularly because our simulations show very good agreement with in situ measurements.

\section{Conclusions}

In summary, we showed that the superposition of highfrequency internal gravity waves with very slow large-scale motions (e.g. driven by Kelvin waves) could trigger homogeneous freezing events in such a way that the low ice crystal number concentrations measured in the TTL are reasonably represented: $\sim 79 \%$ of the ice crystals were formed by "classical" homogeneous freezing in very-slow largescale motions, $\sim 20 \%$ stemmed from combined heterogeneous+homogeneous ice nucleation in very slow large-scale motions, and only $\sim 1 \%$ came from homogeneous freezing with or without simultaneously occurring heterogeneous nucleation in faster large-scale motions. It might be that our results are too simplified in terms of neglecting the superposition of many different wave components, leading to higher concentrations. However, the signature of low crystal number concentrations stemming from slow large-scale motions superimposed by high-frequency waves is a robust signal from our investigations.

There is, therefore, an interplay of the different complementary mechanisms (e.g. TTL dynamics, homogeneous and heterogeneous ice nucleation, as well as the suppression of nucleation by organic substances or crystallization of ammonium sulfate) which may lead to the phenomenon of low ice crystal number concentrations. In order to verify the relative contributions of these different effects, more measurements in the TTL are necessary. To investigate these effects in a more general treatment, additional two- or even threedimensional model simulations including a realistic treatment of gravity waves are important.

Finally, we want to remark that for producing low ice crystal number concentrations correctly in large-scale models, it might be reasonable to switch off the subgrid scale vertical velocities and to trigger nucleation exclusively by large-scale motions in the TTL. Our results suggest that this approach would likely lead to more reasonable ice crystal number concentrations in the TTL for general circulation models as used for climate studies.

\section{Appendix A}

Equations (7) and (10) describe the time evolution of temperature and vertical velocity, respectively. The amplitudes for the wave components for temperature $A_{\mathrm{T}}$ and vertical velocity $A_{\mathrm{w}}$ are related via the intrinsic frequency of the wave $\omega=\frac{2 \pi}{\tau}$, i.e.

$A_{\mathrm{w}}=\frac{c_{p}}{g} \omega \cdot A_{\mathrm{T}}$. 
Table A1. Intrinsic frequencies $N=f \cdot N_{\max }$, periods $\tau=\frac{2 \pi}{N}$ and vertical velocity amplitudes $A_{\mathrm{W}}=\frac{c_{p}}{g} N \cdot A_{\mathrm{T}}$ for different stability regimes $N_{\max }$ using a temperature amplitude of $A_{\mathrm{T}}=1 \mathrm{~K}$.

\begin{tabular}{|c|c|c|c|}
\hline \multicolumn{4}{|c|}{$N_{\max }=0.029 \mathrm{~s}^{-1}$} \\
\hline$f$ & $N\left(\mathrm{~s}^{-1}\right)$ & $\tau(\mathrm{s})$ & $A_{\mathrm{W}}\left(\mathrm{m} \mathrm{s}^{-1}\right)$ \\
\hline 0.4 & 0.011600 & 541.654 & 1.1880 \\
\hline 0.6 & 0.017400 & 361.103 & 1.7820 \\
\hline 0.8 & 0.023200 & 270.827 & 2.3761 \\
\hline 1.0 & 0.029000 & 216.662 & 2.9701 \\
\hline \multicolumn{4}{|c|}{$N_{\max }=0.022 \mathrm{~s}^{-1}$} \\
\hline$f$ & $N\left(\mathrm{~s}^{-1}\right)$ & $\tau(\mathrm{s})$ & $A_{\mathrm{W}}\left(\mathrm{m} \mathrm{s}^{-1}\right)$ \\
\hline 0.4 & 0.008800 & 713.998 & 0.9013 \\
\hline 0.6 & 0.013200 & 475.999 & 1.3519 \\
\hline 0.8 & 0.017600 & 356.999 & 1.8025 \\
\hline 1.0 & 0.022000 & 285.599 & 2.2532 \\
\hline \multicolumn{4}{|c|}{$N_{\max }=0.0172 \mathrm{~s}^{-1}$} \\
\hline$f$ & $N\left(\mathrm{~s}^{-1}\right)$ & $\tau(\mathrm{s})$ & $A_{\mathrm{W}}\left(\mathrm{m} \mathrm{s}^{-1}\right)$ \\
\hline 0.4 & 0.006880 & 913.254 & 0.7046 \\
\hline 0.6 & 0.010320 & 608.836 & 1.0569 \\
\hline 0.8 & 0.013760 & 456.627 & 1.4092 \\
\hline 1.0 & 0.017200 & 365.301 & 1.7616 \\
\hline \multicolumn{4}{|c|}{$N_{\max }=0.0128 \mathrm{~s}^{-1}$} \\
\hline$f$ & $N\left(\mathrm{~s}^{-1}\right)$ & $\tau(\mathrm{s})$ & $A_{\mathrm{W}}\left(\mathrm{m} \mathrm{s}^{-1}\right)$ \\
\hline 0.4 & 0.005120 & 1227.185 & 0.5244 \\
\hline 0.6 & 0.007680 & 818.123 & 0.7866 \\
\hline 0.8 & 0.010240 & 613.592 & 1.0487 \\
\hline 1.0 & 0.012800 & 490.874 & 1.3109 \\
\hline
\end{tabular}

In Table A 1 the values of $\omega=N=f \cdot N_{\max }, \tau$ and $A_{\mathrm{W}}$, respectively, are shown for the realistic set-up as described in Sect. 5.1 for values of $f=0.4 / 0.6 / 0.8 / 1.0$. Here, we assume a temperature amplitude of $A_{\mathrm{T}}=1 \mathrm{~K}$.

Similarly, the vertical displacement $z(t)$ can be described by integrating the equation $\frac{\mathrm{d} z}{\mathrm{~d} t}=w(t)$ via separation of variables, leading to the following expression:

$$
\begin{aligned}
z(t)-z_{0} & =w_{\mathrm{LS}} \cdot t-\underbrace{\frac{A_{\mathrm{w}}}{\omega} \cdot t-\cos (\omega t)}_{\mathrm{LS}} \\
& =\underbrace{\frac{c_{p}}{g} A_{\mathrm{T}}}_{:=A_{z}} \cdot \cos (\omega t) .
\end{aligned}
$$

For values of $A_{\mathrm{T}}=0.1 / 0.25 / 0.5 / 0.75 / 1.0 \mathrm{~K}$ in the realistic set-up in Sect. 5.1 the maximal displacement in terms of amplitudes $A_{z}$ is displayed in Table A2.
Table A2. Amplitudes of temperature $A_{\mathrm{T}}$, and vertical displacement $A_{z}$, respectively.

\begin{tabular}{cccccc}
\hline$A_{\mathrm{T}}(\mathrm{K})$ & 0.1 & 0.25 & 0.5 & 0.75 & 1.0 \\
\hline$A_{z}(\mathrm{~m})$ & 10.24 & 25.60 & 51.21 & 76.81 & 102.42 \\
\hline
\end{tabular}

Acknowledgements. We would like to thank Stephan Borrmann for providing the ice crystal data and Klaus Gierens, Ben Murray, Riwal Plougonven and Holger Tost for fruitful discussions. We also greatly acknowledge Hazel Burlet from the Language Service of the Research Center Jülich for improving the English language of the manuscript. The output from the aerosol model was kindly provided by Debra Weisenstein and Ana Cirisan. This study contributes to the COST action Atmospheric Water Vapour in the Climate System (WaVaCS).

Edited by: W. Lahoz

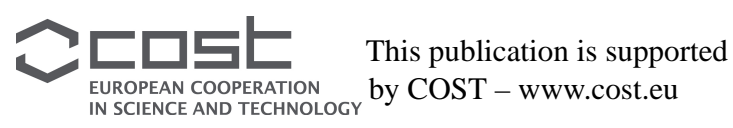

\section{References}

Barahona, D. and Nenes, A. : Parameterization of cirrus cloud formation in large-scale models: Homogeneous nucleation, J. Geophys. Res., 113, D11211, doi:10.1029/2007JD009355, 2008.

Barahona, D. and Nenes, A.: Dynamical states of low temperature cirrus. Atmos. Chem. Phys., 11, 3757-3771, doi:10.5194/acp11-3757-2011, 2011.

Boehm, M. D. and Verlinde, J.: Stratospheric influence on upper tropospheric tropical cirrus, Geophys. Res. Lett., 27, 3209-3212, 2000.

Bretherton, C. S. and Smolarkiewicz, P. K.: Gravity waves, compensating subsidence and detrainment around cumulus clouds, J. Atmos. Sci., 46, 740-759, 1989.

DeMott, P., Cziczo, D., Prenni, A., Murphy, D., Kreidenweis, S., Thomson, D., Borys, R., and Rogers, D.: Measurements of the concentration and composition of nuclei for cirrus formation, $\mathrm{P}$. Natl. Acad. Sci., 100, 14655-14660, 2003.

Flury, T., Wu, D. L., and Read, W. G.: Correlation among cirrus ice content, water vapor and temperature in the TTL as observed by CALIPSO and Aura/MLS, Atmos. Chem. Phys., 12, 683-691, doi:10.5194/acp-12-683-2012, 2012.

Forster, P. M. and Shine, K. P.: Assessing the climate impact of trends in stratospheric water vapor, Geophys. Res. Lett., 29, 1086, doi:10.1029/2001GL013909, 2002.

Fueglistaler, S., Dessler, A. E., Dunkerton, T. J., Folkins, I., Fu, Q., and Mote, P. W.: Tropical Tropopause Layer, Rev. Geophys., 47, RG1004, doi:10.1029/2008RG000267, 2009a.

Fueglistaler, S., Legras, B., Beljaars, A., Morcrette, J.-J., Simmons, A., Tompkins, A. M., and Uppala, S.: The diabatic heat budget of the upper troposphere and lower/mid stratosphere in ECMWF reanalyses, Q. J. Roy. Meteor. Soc., 135, 21-37, 2009 b.

Froyd, K. D., Murphy, D. M., Sanford, T. J., Thomson, D. S., Wilson, J. C., Pfister, L., and Lait, L.: Aerosol composition of the 
tropical upper troposphere, Atmos. Chem. Phys., 9, 4363-4385, doi:10.5194/acp-9-4363-2009, 2009.

Fritts, D. C. and Alexander, M. J.: Gravity wave dynamics and effects in the middle atmosphere, Rev. Geophys., 41, 1003, doi:10.1029/2001RG000106, 2003.

Fujiwara, M., Iwasaki, S., Shimizu, A., Inai, Y., Shiotani, M., Hasebe, F., Matsui, I., Sugimoto, N., Okamoto, H., Nishi, N., Hamada, A., Sakazaki, T., and Yoneyama, K.: Cirrus observations in the tropical tropopause layer over the western Pacific, J. Geophys. Res., 114, D09304, doi:10.1029/2008JD011040, 2009.

Gary, B. L.: Mesoscale temperature fluctuations in the stratosphere, Atmos. Chem. Phys., 6, 4577-4589, doi:10.5194/acp-6-45772006, 2006.

Gensch, I., Bunz, H., Baumgardner, D., Christensen, L., Fahey, D., Hermann, R., Lawson, P., Popp, P., Smith, J., Webster, C., Weinstock, E., Wilson, J., Peter, T., and Krämer, M.: Supersaturations, Microphysics and Nitric Acid Partitioning in a Cold Cirrus observed during CR-AVE 2006: An ObservationModeling Intercomparison Study, Environ. Res. Lett., 3, 035003, doi:10.1088/1748-9326/3/3/035003, 2008.

Gierens, K., Kohlhepp, R., Dotzek, N., and Smit, H. G.: Instantaneous fluctuations of temperature and moisture in the upper troposphere and tropopause region. Part 1: Probability densities and their variability, Meteorol. Z., 16, 221-231, 2007.

Gill, A. E.: Some simple solutions for heat-induced tropical circulation, Q. J. Roy. Meteor. Soc., 106, 447-462, 1980.

Hertzog, A. and Vial, F.: A study of the dynamics of the equatorial lower stratosphere by use of ultra-long-duration balloons 2 . Gravity waves, J. Geophys. Res., 106, 22745-22761, 2001.

Hoyle, C., Luo, B., and Peter, T.: The Origin of High Ice Crystal Number Densities in Cirrus Clouds, J. Atmos. Sci., 62, 25682579, 2005.

Immler, F., Krüger, K., Fujiwara, M., Verver, G., Rex, M., and Schrems, O.: Correlation between equatorial Kelvin waves and the occurrence of extremely thin ice clouds at the tropical tropopause, Atmos. Chem. Phys., 8, 4019-4026, doi:10.5194/acp-8-4019-2008, 2008.

Jensen, E. and Pfister, L.: Transport and freeze-drying in the tropical tropopause layer, J. Geophys. Res., 109, D02207, doi:10.1029/2003JD004022, 2004.

Jensen, E. J., Pfister, L., Bui, T. V., Lawson, P., Baker, B., Mo, Q., Baumgardner, D., Weinstock, E. M., Smith, J. B., Moyer, E. J., Hanisco, T. F., Sayres, D. S., Clair, J. M. St., Alexander, M. J., Toon, O. B., and Smith, J. A.: Formation of large $(\simeq 100 \mu \mathrm{m})$ ice crystals near the tropical tropopause, Atmos. Chem. Phys., 8 , 1621-1633, doi:10.5194/acp-8-1621-2008, 2008.

Jensen, E. J., Pfister, L., Bui, T.-P., Lawson, P., and Baumgardner, D.: Ice nucleation and cloud microphysical properties in tropical tropopause layer cirrus, Atmos. Chem. Phys., 10, 1369-1384, doi:10.5194/acp-10-1369-2010, 2010.

Jensen, E. J., Diskin, G., Lawson, R. P., Lance, S., Bui, T. P., Hlavka, D., McGill, M., Pfister, L., Toon, O. B., and Gao, R.: Ice nucleation and dehydration in the Tropical Tropopause Layer, P. Natl. Acad. Sci., 110, 2041-2046, doi:10.1073/pnas.1217104110, 2013.

Kajikawa, M. and Heymsfield, A.: Aggregation of ice crystals, J. Atmos. Sci., 46, 3108-3121, 1989.
Kärcher, B. and Koop, T.: The role of organic aerosols in homogeneous ice formation, Atmos. Chem. Phys., 5, 703-714, doi:10.5194/acp-5-703-2005, 2005.

Kärcher, B. and Lohmann, U.: A parameterization of cirrus cloud formation: Homogeneous freezing of supercooled aerosols, J. Geophys. Res., 107, 4010, doi:10.1029/2001JD000470, 2002.

Khvorostyanov, V., Morrison, H., Curry, J., Baumgardner, D., and Lawson, P.: High supersaturation and modes of ice nucleation in thin tropopause cirrus: Simulation of the 13 July 2002 Cirrus Regional Study of Tropical Anvils and Cirrus Layers case, J. Geophys. Res., 111, D02201, doi:10.1029/2004JD005235, 2006.

Koop, T., Luo, B., Tsias, A., and Peter, T.: Water activity as the determinant for homogeneous ice nucleation in aqueous solutions, Nature, 406, 611-614, 2000.

Korolev, A. and Mazin, I.: Supersaturation of Water Vapor in Clouds, J. Atmos. Sci., 60, 2957-2974, 2003.

Krämer, M., Schiller, C., Afchine, A., Bauer, R., Gensch, I., Mangold, A., Schlicht, S., Spelten, N., Sitnikov, N., Borrmann, S., de Reus, M., and Spichtinger, P.: Ice supersaturations and cirrus cloud crystal numbers, Atmos. Chem. Phys., 9, 3505-3522, doi:10.5194/acp-9-3505-2009, 2009.

Lawson, R. P., Pilson, B., Baker, B., Mo, Q., Jensen, E., Pfister, L., and Bui, P.: Aircraft measurements of microphysical properties of subvisible cirrus in the tropical tropopause layer, Atmos. Chem. Phys., 8, 1609-1620, doi:10.5194/acp-8-1609-2008, 2008.

Lin, H., Noone, K. J., Ström, J., and Heymsfield, A. J.: Dynamical Influences on Cirrus Cloud Formation Process, J. Atmos. Sci., 55, 1940-1949, 1998.

McFarquhar, G. M., Heymsfield, A. J., Spinhirne, J., and Hart, B.: Thin and Subvisual Tropopause Tropical Cirrus: Observations and Radiative Impacts, J. Atmos. Sci., 57, 1841-1853, 2000.

Murray, B. J.: Inhibition of ice crystallisation in highly viscous aqueous organic acid droplets, Atmos. Chem. Phys., 8, 54235433, doi:10.5194/acp-8-5423-2008, 2008.

Murray, B., Wilson, T. W., Dobbie, S., Cui, Z., Al-Jumur, S. M. R. K., Möhler, O., Schnaiter, M., Wagner, R., Benz, S., Niemand, M., Saathoff, H., Ebert, V., Wagner, S., and Kärcher, B.: Heterogeneous nucleation of ice particles on glassy aerosols under cirrus conditions, Nat. Geosci., 3, 233-237, doi:10.1038/NGEO817, 2010.

Peter, T., Marcolli, C., Spichtinger, P., Corti, T., Baker, M. B., and Koop, T.: When dry air is too humid, Science, 314, 1399-1402, 2006.

Ruprecht, D. and Klein, R.: A Model for Nonlinear Interactions of Internal Gravity Waves with Saturated Regions, Meteorol. Z., 20, 243-252, 2011.

Ruprecht, D., Klein, R., and Majda, A. J.: Modulation of Internal Gravity Waves in a Multiscale Model for Deep Convection on Mesoscales, J. Atmos. Sci., 67, 2504-2519, 2010.

Ryu, J.-H. and Lee, S.: Effect of Tropical Waves on the Tropical Tropopause Transition Layer Upwelling, J. Atmos. Sci., 67, 3130-3148, 2010.

Salby, M. and Callaghan, P.: Control of the Tropical Tropopause and Vertical Transport across It, J. Climate, 17, 965-985, 2004.

Schiller, C., Krämer, M., Afchine, A., Spelten, N., and Sitnikov, N.: The ice Water Content in Arctic, Midlatitude and Tropical Cirrus, J. Geophys. Res., 113, D24208, doi:10.1029/2008JD010342, 2008. 
Seifert, A. and Beheng, K. D.: : A two-moment cloud microphysics parameterization for mixed-phase clouds. Part 1: Model description, Meteorol. Atmos. Phys., 92, 45-66, 2006.

Selkirk, H. B., Vömel, H., Valverde Canossa, J. M., Pfister, L., Diaz, J. A., Fernández, W., Amador, J., Stolz, W., and Peng, G. S.: Detailed structure of the tropical upper troposphere and lower stratosphere as revealed by balloon sonde observations of water vapor, ozone, temperature, and winds during the NASA TCSP and TC4 campaigns, J. Geophys. Res., 115, D00J19, doi:10.1029/2009JD013209, 2010.

Spichtinger, P. and Cziczo, D. J.: Impact of heterogeneous ice nuclei on homogeneous freezing events in cirrus clouds, J. Geophys. Res., 15, D14208, doi:10.1029/2009JD012168, 2010.

Spichtinger, P. and Gierens, K. M.: Modelling of cirrus clouds Part 1a: Model description and validation, Atmos. Chem. Phys., 9, 685-706, doi:10.5194/acp-9-685-2009, 2009a.

Spichtinger, P. and Gierens, K. M.: Modelling of cirrus clouds - Part 1b: Structuring cirrus clouds by dynamics, Atmos. Chem. Phys., 9, 707-719, doi:10.5194/acp-9-707-2009, 2009b.

Spichtinger, P. and Gierens, K. M.: Modelling of cirrus clouds - Part 2: Competition of different nucleation mechanisms, Atmos. Chem. Phys., 9, 2319-2334, doi:10.5194/acp-9-2319-2009, 2009c.

Thomas, A., Borrmann, S., Kiemle, C., Cairo, F., Volk, M., Beuermann, J., Lepuchov, B., Santacesaria, V., Matthey, R., Rudakov, V., Yushkov, V., MacKenzie, A. R., and Stefanutti, L.: In situ measurements of background aerosol and subvisible cirrus in the tropical tropopause region, J. Geophys. Res., 107, 4763, doi:10.1029/2001JD001385, 2002.

Thompson, A. M., Witte, J. C., McPeters, R. D., Oltmans, S. J., Schmidlin, F. J., Logan, J. A., Fujiwara, M., Kirchhoff, V. W. J. H., Posny, F., Coetzee, G. J. R., Hoegger, B., Kawakami, S., Ogawa, T., Johnson, B. J., Vömel, H., and Labow, G.: Southern Hemisphere Additional Ozonesondes (SHADOZ) 1998-2000 tropical ozone climatology 1. Comparison with Total Ozone Mapping Spectrometer (TOMS) and ground-based measurements, J. Geophys. Res., 108, 8238, doi:10.1029/2001JD000967, 2003.
Thompson, A. M., Allen, A. L., Lee, S., Miller, S. K., and Witte, J. C.: Gravity and Rossby wave signatures in the tropical troposphere and lower stratosphere based on Southern Hemisphere Additional Ozonesondes (SHADOZ), 1998-2007, J. Geophys. Res., 116, D05302, doi:10.1029/2009JD013429, 2011.

Vial, F., Hertzog, A., Mechoso, C. R., Basdevant, C., Cocquerez, P., Dubourg, V., and Nouel, F.: A study of the dynamics of the equatorial lower stratosphere by use of ultra-long-duration balloons, 1. Planetary scales, J. Geophys. Res., 106, 22725-22743, 2001.

Virts, K.: Cirrus in the Tropical Tropopause Transition Layer: Formation Mechanisms and Influence of the Local and PlanetaryScale Environment, MSc thesis, University of Washington, 108 pp., available at: http://www.atmos.washington.edu/ kvirts/ docs/Thesis.pdf, 2009

Virts, K., Wallace, J., Fu, Q., and Ackermann, T.: Tropical Tropopause Transition Layer Cirrus as Represented by CALIPSO Lidar Observations, J. Atmos. Sci., 67, 3113-3129, 2010.

Wang, L., Alexander, M. J., Bui, T. B., and Mahoney, M. J.: Smallscale gravity waves in ER-2 MMS/MTP wind and temperature measurements during CRYSTAL-FACE, Atmos. Chem. Phys., 6, 1091-1104, doi:10.5194/acp-6-1091-2006, 2006.

Webster, P. J.: Response of the tropical atmosphere to local, steady forcing, Mon. Weather Rev., 100, 518-541, 1972.

Weisenstein, D. K., Penner, J. E., Herzog, M., and Liu, X.: Global 2$\mathrm{D}$ intercomparison of sectional and modal aerosol modules, Atmos. Chem. Phys., 7, 2339-2355, doi:10.5194/acp-7-2339-2007, 2007.

Wheeler, M., Kiladis, G. N., and Webster, P. J.: Large-scale dynamical fields associated with convectively coupled equatorial waves, J. Atmos. Sci., 57, 613-640, 2000.

Zobrist, B., Marcolli, C., Pedernera, D. A., and Koop, T.: Do atmospheric aerosols form glasses?, Atmos. Chem. Phys., 8, 52215244, doi:10.5194/acp-8-5221-2008, 2008. 